\title{
Quality assessment of water cycle parameters in REMO by radar-lidar synergy
}

\author{
B. Hennemuth ${ }^{1, *}$, A. Weiss ${ }^{2}$, J. Bösenberg ${ }^{1}$, D. Jacob ${ }^{1}$, H. Linné ${ }^{1}$, G. Peters ${ }^{3}$, and S. Pfeifer ${ }^{1}$ \\ ${ }^{1}$ Max-Planck-Institute for Meteorology, Hamburg, Germany \\ ${ }^{2}$ British Antarctic Survey, High Cross, Madingley Road, Cambridge CB3 0ET, UK \\ ${ }^{3}$ Meteorological Institute, University of Hamburg, Hamburg, Germany \\ * now at: Consulting Meteorologist, Hamburg, Germany
}

Received: 30 May 2007 - Published in Atmos. Chem. Phys. Discuss.: 20 June 2007

Revised: 23 November 2007 - Accepted: 7 December 2007 - Published: 25 January 2008

\begin{abstract}
A comparison study of water cycle parameters derived from ground-based remote-sensing instruments and from the regional model REMO is presented. Observational data sets were collected during three measuring campaigns in summer/autumn 2003 and 2004 at Richard Aßmann Observatory, Lindenberg, Germany. The remote sensing instruments which were used are differential absorption lidar, Doppler lidar, ceilometer, cloud radar, and micro rain radar for the derivation of humidity profiles, ABL height, water vapour flux profiles, cloud parameters, and rain rate. Additionally, surface latent and sensible heat flux and soil moisture were measured. Error ranges and representativity of the data are discussed. For comparisons the regional model REMO was run for all measuring periods with a horizontal resolution of $18 \mathrm{~km}$ and 33 vertical levels. Parameter output was every hour. The measured data were transformed to the vertical model grid and averaged in time in order to better match with gridbox model values. The comparisons show that the atmospheric boundary layer is not adequately simulated, on most days it is too shallow and too moist. This is found to be caused by a wrong partitioning of energy at the surface, particularly a too large latent heat flux. The reason is obviously an overestimation of soil moisture during drying periods by the one-layer scheme in the model. The profiles of water vapour transport within the ABL appear to be realistically simulated. The comparison of cloud cover reveals an underestimation of low-level and mid-level clouds by the model, whereas the comparison of high-level clouds is hampered by the inability of the cloud radar to see cirrus clouds above $10 \mathrm{~km}$. Simulated ABL clouds apparently have a too low cloud base, and the vertical extent is under-
\end{abstract}

Correspondence to: B. Hennemuth

(hennemuth@dkrz.de) estimated. The ice water content of clouds agree in model and observation whereas the liquid water content is unsufficiently derived from cloud radar reflectivity in the present study. Rain rates are similar, but the representativeness of both observations and grid box values is low.

\section{Introduction}

Regional climate models are widely used to assess regional climatic features for present climate and increasingly also for future climate, e.g. to downscale global change scenarios for the analysis of regional climate change and its impacts. For these studies, the validation of models, e.g. comparisons of model simulations with observations are an essential prerequisite to ensure that the main processes are simulated properly. One of the key processes is the water cycle, controlling cloud formation and precipitation. A crucial question is whether there will be an accelerated water cycle in the future. Therefore, the ability of models to simulate the complete water cycle of present day climate must be tested. Of special interest are cloud parameters because of their strong impact on radiation, and thus on energetic issues. Moreover, the formation of precipitation is a crucial point for the assessment of climate. Special interest should also be directed to boundary layer parameters because of the great turnover of water and energy in this layer adjacent to the earth's surface.

Ground-based remote sensing systems are adequate instrumentation for model comparison of water cycle parameters since a several quantities can be derived simultaneously, and they cover a wide range of heights and operate continuously. There has been enormous progress in the development and refinement of ground-based remote sensing instruments for

Published by Copernicus Publications on behalf of the European Geosciences Union. 
Table 1. Characteristics of lidar systems and cloud radar.

\begin{tabular}{lccc}
\hline & DIAL & Doppler lidar & Cloud radar \\
\hline Wavelength & $0.82 \times 10^{-6} \mathrm{~m}$ & $1.12 \times 10^{-6} \mathrm{~m}$ & $8 \times 10^{-3} \mathrm{~m}$ \\
Meas. value & $a$ & $w$ & $Z$ \\
Meas. time & daytime & daytime & continuous \\
Time resol. & $10 \mathrm{~s}$ & $10 \mathrm{~s}$ & $60 \mathrm{~s}$ \\
Min. height & $400 \mathrm{~m}$ & $200 \mathrm{~m}$ & $150 \mathrm{~m}$ \\
Max. height & $3000 \mathrm{~m}$ & top of ABL & $13500 \mathrm{~m}$ \\
Height resol. & $90 \mathrm{~m}$ & $90 \mathrm{~m}$ & $30 \mathrm{~m}$ \\
Instrum. error & $<0.2 \mathrm{gm}^{-3}$ & $<0.1 \mathrm{~m} \mathrm{~s}^{-1}$ & $-50 \mathrm{dBZ}$ \\
\hline
\end{tabular}

the determination of humidity, wind, cloud parameters and rain rate in recent years (e.g., Bösenberg and Linné, 2002; Haeffelin et al., 2005; Peters et al., 2002; Intrieri et al., 2002), and also the retrieval algorithms for characterising clouds have been much improved in recent years, not least because of international projects like BALTEX BRIDGE with its subprogramm CLIWA-NET and CLOUDNET (http: //www.cloud-net.org), and the German 4D CLOUDS project (e.g., Crewell et al., 2004; Löhnert et al., 2004). In particular the CLOUDNET project has promoted the retrievals of cloud liquid water and cloud ice water content (e.g., Tinel et al., 2005; Liu and Illingworth, 2000; Hogan et al., 2006).

Many model validation studies concentrate on single parameters such as evaporation, precipitation, boundary layer height, or cloud parameters (e.g., Chiriaco et al., 2006). Precipitation comparisons are rather frequent, because precipitation observations are available with a good resolution due to a dense rain gauge network over land and radar networks e.g. over the Baltic Sea region (Jacob, 2001). Within CLOUDNET and CLIWA-NET extensive comparisons of the observed cloud structure with several operational forecast models like ECMWF model, RACMO, RCA and LM with horizontal resolution between $50 \mathrm{~km}$ and $7 \mathrm{~km}$ were performed (Willén et al., 2005).

In this study, an integral evaluation of the water cycle simulated by a model with observations is tried. The water cycle parameters measured at the Meteorological Observatory Lindenberg (MOL), Germany, during experiments in summer and autumn 2003 and 2004 are compared with simulated parameters of the regional model REMO. The comparisons include vertical distribution of humidity in the lower troposphere, surface evaporation, soil moisture, profiles of vertical water vapour flux in the boundary layer, cloud cover, vertical distribution of cloud boundaries, cloud water and ice, and precipitation. Special attention is paid to the atmospheric boundary layer (ABL), particularly to the convective boundary layer (CBL) because of its important role in controlling the water transport between the earth's surface and the free atmosphere. The data set is used for statistical analysis as well as for process studies. Special emphasis is given on the assessment of the differences between observed and modelled values with regard to measurement accuracy.

\section{Observations}

\subsection{Instrumentation}

\subsubsection{Lidar systems}

Water Vapour Lidar

The MPI-DIAL (Differential Absorption Lidar) is a vertically pointing water vapour lidar. It combines signals at two slightly different wavelengths. One wavelength is located in the centre of a water vapour absorption line ("online"), the other is located just beside but in a region of negligible water vapour absorption ("offline"). The backscatter coefficient can be assumed to be the same for both wavelengths, so the ratio of the two signals depends only on water vapour absorption (absolute humidity $a$ ). For details of the methodology the reader is referred to Bösenberg (1998, 2005). Typical performance values are summarised in Table 1, but lower resolution and/or decreased accuracy may occur in the upper altitude range. The measurement error caused by noise is nearly constant with height within the boundary layer and strongly increases in the free atmosphere. Table 1 gives the error range within the boundary layer. The backscatter measurement has a vertical resolution of $15 \mathrm{~m}$.

During the first campaign a different laser type was used (Wulfmeyer and Bösenberg, 1998) than in the later campaigns (Ertel, 2004). Due to the different configuration and adjustment the height interval was $700 \mathrm{~m}$ to $4000 \mathrm{~m}$ in 2003 and $300 \mathrm{~m}$ to $3000 \mathrm{~m}$ in 2004 . The operating time was daytime only.

\section{Doppler Lidar}

For vertical wind speed measurements a Doppler lidar (MPI Hamburg) with heterodyne detection, operating at $1120 \mathrm{~nm}$ wavelength was used. The instrument is described by Linné et al. (2007). The performance depends on the presence of aerosol particles of sufficient size to produce backscatter at the operating wavelength of $1120 \mathrm{~nm}$, so wind data are mainly collected in the boundary layer. Typical performance values are summarised in Table 1 . The noise induced error estimated from the power spectrum is less than $0.1 \mathrm{~m} \mathrm{~s}^{-1}$ within the boundary layer. Both lidar systems, DIAL and Doppler lidar were only operated during daytime because unattended operation was not feasible at that time. 


\section{Ceilometer}

The Laser-Ceilometer Tropopauser LD40 (Impulsphysik $\mathrm{GmbH})$ operates at $855 \mathrm{~nm}$ to detect cloud base heights. Only standard products of the online signal processing software were used which include the detection of up to three cloud levels with a time resolution of $10 \mathrm{~min}$ and a height resolution of $25 \mathrm{~m}$. It operates continuously but its sensitivity is much smaller than that of the DIAL.

\subsubsection{Radar systems}

\section{Cloud radar}

The cloud radar MIRA-36 (METEK GmbH) is a vertically pointing Doppler radar, measuring at a frequency of $36.5 \mathrm{GHz}$ corresponding to $8 \mathrm{~mm}$ wavelength (Bormotov et al., 2000). It provides the radar reflectivity factor $Z$ which is equal to the 6th moment of the drop size distribution $N(D)$ for drops with diameter $D \ll \lambda$ (Rayleigh approximation). In addition to $Z$, the Doppler velocity $V$ and the linear depolarization ratio LDR are recorded since these variables are useful for target classification. Main operating parameters of the radar are given in Table 1.

The interpretation of radar reflectivities in terms of cloud properties requires some caution since signals at the radar receiver input are not necessarily due to cloud echoes. In addition to the unavoidable noise floor at the receiver input, backscatter from drizzle droplets may dominate the radar reflectivity, even if drizzle may contribute only little to LWC within a cloud. Other radar echoes - particularly in the atmospheric boundary layer - may stem from suspended atmospheric particles (see Sect. 2.2.5). To some extent these contributions to the radar reflectivity could be separated based on their characteristic frequency distributions, but the remaining ambiguities underline the need of further information in order to derive sensible cloud statistics. As discussed in Sect. 2.2.5, simultaneous lidar echoes were used in this study to remove efficiently the boundary-layer particle signal. In the same way drizzle induced ambiguities were mitigated - however at this stage only with regard to cloud base detection, but not to liquid water estimation.

\section{Micro rain radar}

The micro rain radar MRR (METEK GmbH) measures the size distribution of rain droplets at 32 heights from which rain parameters, including the rainrate, can be derived (Peters et al., 2002, 2005). The measuring frequency is $24.1 \mathrm{GHz}$. The height interval was $50 \mathrm{~m}$ in 2003 and $100 \mathrm{~m}$ in 2004. The lowest useful height is the third range gate $(150 \mathrm{~m} / 300 \mathrm{~m})$ which was used in this study. The retrieval of size distribution is based on the size-dependent terminal fall velocity of rain drops. Vertical air motion is the dominating source of error. In terms of rain rate the error is $25 \%$ per
$0.1 \mathrm{~m} \mathrm{~s}^{-1}$ vertical wind. For $1 \mathrm{~min}$ averages the estimated standard deviation of the statistical rain rate error is $\pm 20 \%$ under conditions typical for these data sets.

\subsubsection{Other instrumentation}

In the area around MOL a network of global radiation instruments and of 14 PLUVIO rain gauges $(\mathrm{Ott} \mathrm{GmbH})$ is installed in order to characterize the variability of the forcing for the water and energy cycle. The sensitivity threshold of the PLUVIO sensor corresponds to a rain amount of $0.03 \mathrm{~mm}$, smaller amounts can not be recorded. Continuous precipitation of weak intensity is therefore reported as a series of single events. Each accumulation of mass in the gauge is reported by the sensor as precipitation (e.g., heavy insects). Therefore, isolated single values at the detection limit have usually to be interpreted as questionable or corrupted data.

During the first measuring period a network of energy balance stations was installed for the determination of areaaveraged surface fluxes. 13 micrometerological and flux stations were operated over different types of soil, vegetation and land use. All stations were equipped with ultrasonic-anemometer-thermometers and fast-response optical hygrometers for the determination of the surface turbulent sensible and latent heat fluxes by eddy-covariance techniques. Details on the measurement sites and instrumentation can be found in Beyrich et al. (2006). Processing and quality control of the data at all sites were performed with one standard software package which is described by Mauder et al. (2006) who specify the error for sensible heat flux as $5 \%$ and for latent heat flux as $15 \%$.

Seven energy balance stations were equipped with instruments for the measurement of soil moisture at different depths.

\subsection{Measured parameters and accuracy}

\subsubsection{Surface evaporation, soil moisture}

In order to obtain area-averaged surface fluxes of latent and sensible heat from the energy balance network, flux composites were derived for each surface type by averaging data from the different stations operated over the same type of surface. Then averages for the three main land use classes (farmland, forest, water) and a weighted area-average over the whole study region were determined considering the percentage of each surface type in the area (for details, see Beyrich et al., 2006). For this study only the composite flux values for farmland were used because this is the prevailing land use class in the corresponding model gridbox (see Sect. 3). The averaging time is $30 \mathrm{~min}$. The uncertainty range of composite fluxes is determined by Beyrich et al. (2006) and is approximately $10 \%$ for sensible heat flux and $15-20 \%$ for latent heat flux. 

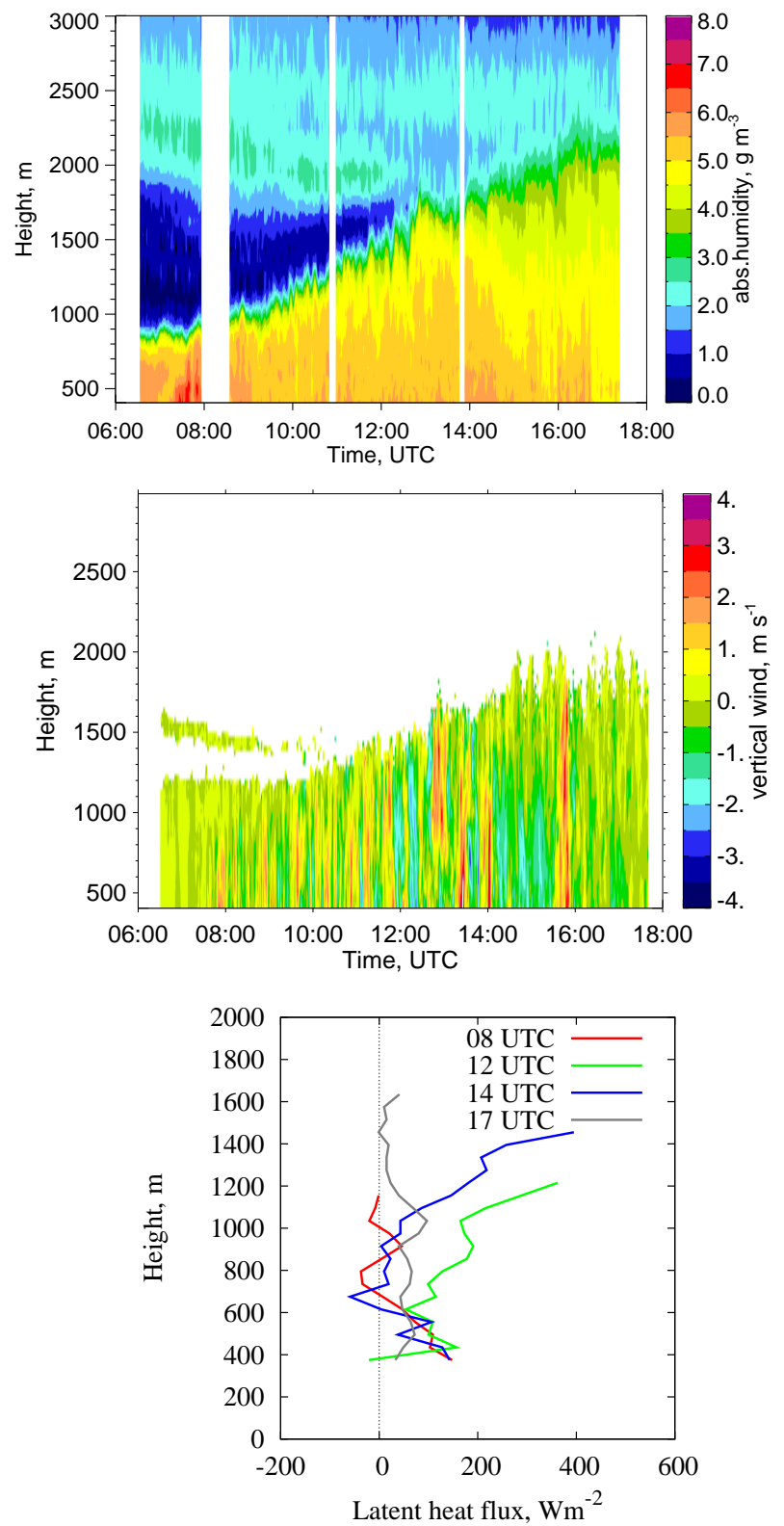

Fig. 1. Time-height cross-sections of absolute humidity (top) and vertical wind (middle) and derived latent heat flux profiles (bottom) on 30 May 2003.

Soil moisture data are not averaged because the measurements at different locations differ strongly - although the trends are similar - and measurement depths differ, too. One location with continuous measurements is chosen as a proxy and the data are only compared qualitatively with model data.

\subsubsection{Humidity field}

From DIAL measurements vertical profiles of absolute humidity with a time resolution of $10 \mathrm{~s}$ can be derived. As Fig. 1 (upper panel) shows, the humidity structure in the lower troposphere, in particular the evolution of the convective boundary layer is well depicted.

The accuracy of the derived absolute humidity values is determined by systematic errors which are small and well assessed (Bösenberg, 1998) and by random errors which depend on atmospheric conditions, height, and resolution. Actual random errors are estimated for each measurement. For the $\mathrm{ABL}$ altitude range and typical conditions during the measurements presented here a value of $<0.2 \mathrm{gm}^{-3}$ can be assumed.

\subsubsection{Vertical water vapour transport}

The water vapour flux was determined by the eddycovariance method from fluctuations of humidity and vertical wind measured by synchronised DIAL and Doppler lidar, operating side by side. The measurements, which took place during the first campaign, are described by Linné et al. (2007). Flux values are calculated at $30 \mathrm{~m}$ intervals with an averaging period of $90 \mathrm{~min}$. Since wind data are only available in aerosol loaded layers, the flux values are mainly restricted to the boundary layer and often do not capture the strong gradient at the top of the ABL. Figure 1 illustrates the availability of vertical wind and humidity fluctuation measurements and derived water vapour flux profiles at special time intervals. Depending on the mean horizontal wind speed the recorded dominating eddies may have a time scale of up to $30 \mathrm{~min}$ which leads to a rather large sampling error. Typical total error values for $90 \mathrm{~min}$ average flux values are $\pm 50 \mathrm{Wm}^{-2}$ (Linné et al., 2007).

\subsubsection{Boundary layer height}

The boundary layer height is derived from the DIAL offline backscatter signal. The method of Lammert and Bösenberg (2006) is used which is based on the analysis of average and instantaneous data by searching for the maximum in the vertical variance profile and the maximum in the gradient profile of the backscatter signal. The method has been modified by implementation of a cloud mask (see Sect. 2.2.5) so that only in cloud-free regions the ABL height is determined as is illustrated by Fig. 2. The $10 \mathrm{~s}$ boundary layer heights are averaged over one minute.

During clear-sky conditions the top of the CBL is well detected. Some problems exist in finding the growing CBL height in the early morning and in the late evening when the residual layer may be misinterpreted as the boundary layer. For these reasons the comparisons with REMO will be restricted to the fully developed CBL between 10:00 and 16:00 UTC. 
The height resolution of CBL-height is $15 \mathrm{~m}$. The accuracy strongly depends on atmospheric conditions and is estimated in a cloud-free and well-defined CBL as better than $50 \mathrm{~m}$, but deviations due to ill-defined ABL may be as large as $200 \mathrm{~m}$ (Hennemuth and Lammert, 2006).

\subsubsection{Cloud parameters}

Scattering of millimeter waves is particularly suited to characterise cloud parameters because most clouds can on one hand be detected and on the other hand are penetrated, even if there are multiple optically thick cloud layers. Cloud parameters to be determined by radar are cloud cover, cloud boundaries and thickness, number of layers, liquid water content and ice water content.

Main ambiguities in cloud parameter retrieval from radar reflectivity are due to the proportionality to the 6th moment of the cloud drop size distribution $N(D)$. Thus quantitative retrieval of liquid water content (proportional to the third moment of $N(D)$ ) is obviously impossible without assumptions on the shape of $N(D)$. Even the observed cloud boundaries are sometimes affected by the $\mathrm{D}^{6}$-dependence of the radar echo.

Particularly cloud-base detection in the boundary layer can be impaired by mainly two mechanisms:

- Clouds often release small amounts of drizzle, which evaporates at some height between the cloud base and the surface. As drizzle drops are larger than cloud drops, they tend to dominate the radar echo due to the $\mathrm{D}^{6}$ dependence, even if their liquid water content is negligible.

- During daytime in the warm season particulate echos from the cloud-free boundary layer can be misinterpreted as clouds. Insects or seeds are assumed to be the main source of these echos (sometimes referred to as "atmospheric plankton").

In addition, optical relevant clouds can sometimes fall below the detection threshold of the radar when cloud particles are too small. This occurs preferably in shallow convective ABL clouds (e.g. cumulus humilis) or in high cirrus clouds.

In this study only the radar reflectivity factor $Z$ was considered, although spectral and polarimetric data with high potential to mitigate many of the mentioned shortcomings were provided by the radar. This restriction was dictated by the lack of sufficiently tested algorithms to exploit this information except for case studies and by the fact that those data were not continuously available.

Optical ceilometer data, which were continuously available, provided an alternative to eliminate the cloud base ambiguities. Due to the $\mathrm{D}^{2}$-dependence of the optical returns for the given range of particle sizes drizzle and atmospheric plankton had nearly no effect on optical data. Therefore ceilometer data, and if available, DIAL data were used to

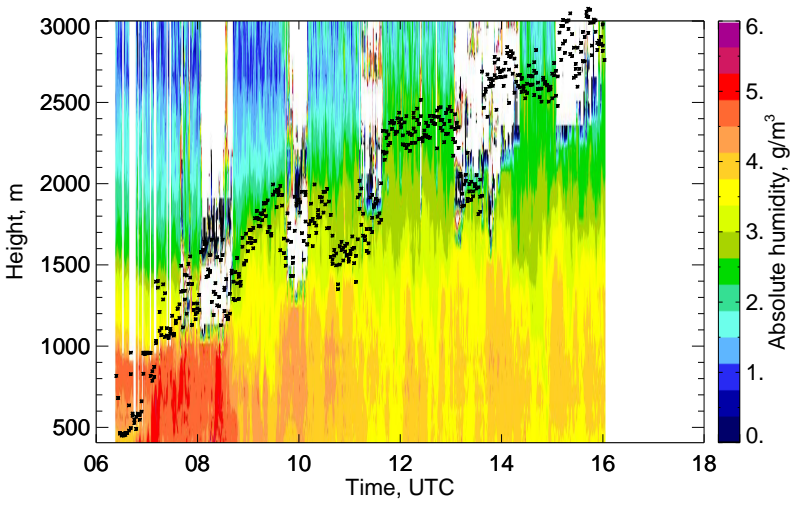

Fig. 2. Boundary layer height plotted over time-height cross-section of absolute humidity 28 May 2004. The clouds are masked.

determine the lowest cloud base in the ABL. In addition the comparison of radar and DIAL data provides an estimate of the fraction of high cirrus clouds below the radar detection threshold. The ratio of clouds detected only by lidar and of clouds detected in the same interval by radar and lidar is 2.7 for the height range of $9 \mathrm{~km}$ to $12 \mathrm{~km}$. Since this number is only valid for times where a lidar detects an ice cloud, i.e. for rather dry periods, a generalization is not possible as is stated by Protat et al. (2006). But the necessity of using an additional optical instrument for the detection of high Cirrus clouds is underlined.

Cloud base determination with ceilometer relies completely on the proprietary algorithm of the system manufacturer. According to C. Münkel (personal communication) the algorithm first identifies rain sections in the lowest $2000 \mathrm{~m}$ of the range- and overlap-corrected signal profile by checking signal strength and height range threshold values. Clouds can be detected within and outside rain sections by either checking the slope steepness or signal strength. The cloud base height is set to $15 \mathrm{~m}$ below the height of the maximum signal within the cloud peak.

In about $30 \%$ of times the offline channel of the DIAL was used for cloud detection with very high sensitivity. Only signals with a signal-to-noise-ratio $\mathrm{SNR}>5$ are used, and cloud boundary detection is based on the analysis of the small scale variances $(40 \mathrm{~ms} / 15 \mathrm{~m}$ resolution). Since backscatter shows a sharp increase at cloud boundaries and the edges are variable in time and height, the shot-to-shot signal variance shows a pronounced maximum at the cloud boundaries. Signal strength is used additionally to select only those variance maxima associated with clouds.

Different cloud detection algorithms exist, based on the maximum in the backscatter coefficient profile (Hogan et al., 2003) or on a wavelet analysis (Haeffelin et al., 2005), used at the SIRTA site (France). A systematic algorithm 


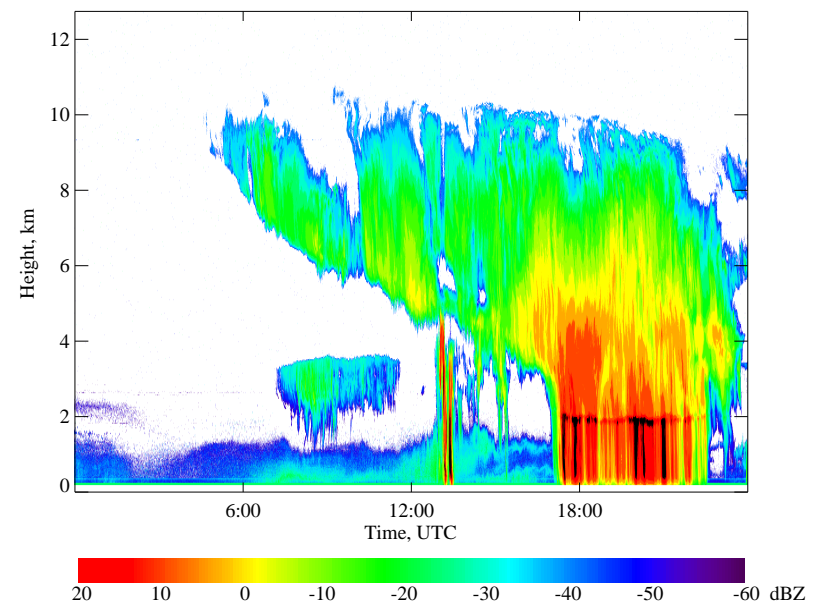

Fig. 3. Time-height cross-section of the effective radar reflectivity factor on 4 June 2004.

comparison was beyond the scope of this study.

\section{Cloud morphology}

Vertical profiles of cloud boundaries were derived with a resolution of $\Delta \mathrm{t}=1 \mathrm{~min}, \Delta \mathrm{z}=30 \mathrm{~m}$. The automatic detection of clouds with radar requires the knowledge of the noise level $P_{n}$ at the radar receiver input. In this study $P_{n}$ was obtained from the receiver signal, measured after the transmit pulse with a delay corresponding to $12 \mathrm{~km}$ height. With knowledge of $P_{n}$ and of the number of incoherent averages $N$ a detection threshold for echo power $P$ was defined according $P>P_{n}(1+1 / \sqrt{N})$. Depending on the spatial and temporal coherence of the detection condition in $P$-fields comprising 5 pixels in range and 5 pixels in time a cloud mask was established as described by Clothiaux et al. (1995).

Figure 3 illustrates that multiple cloud layers are penetrated by the radar. The echos from particles inside the ABL, which have to be masked with lidar data, are clearly visible. Rain events can be detected by the Doppler velocity.

For the same day the range-corrected backscatter signal of the offline channel of the DIAL and the derived cloud mask are shown in Fig. 4.

The complete cloud mask is then derived from the combination of both instruments by using lidar data for lowest cloud base height, radar data for cloud top heights and cloud base heights above water cloud layers. This method was also applied by Intrieri et al. (2002). Figure 5 clearly shows that the lidar beam cannot penetrate water clouds because the signal is rapidly attenuated by strong scattering from water droplets. High cirrus clouds and some low-level smallparticle clouds on the other hand are invisible for the cloud
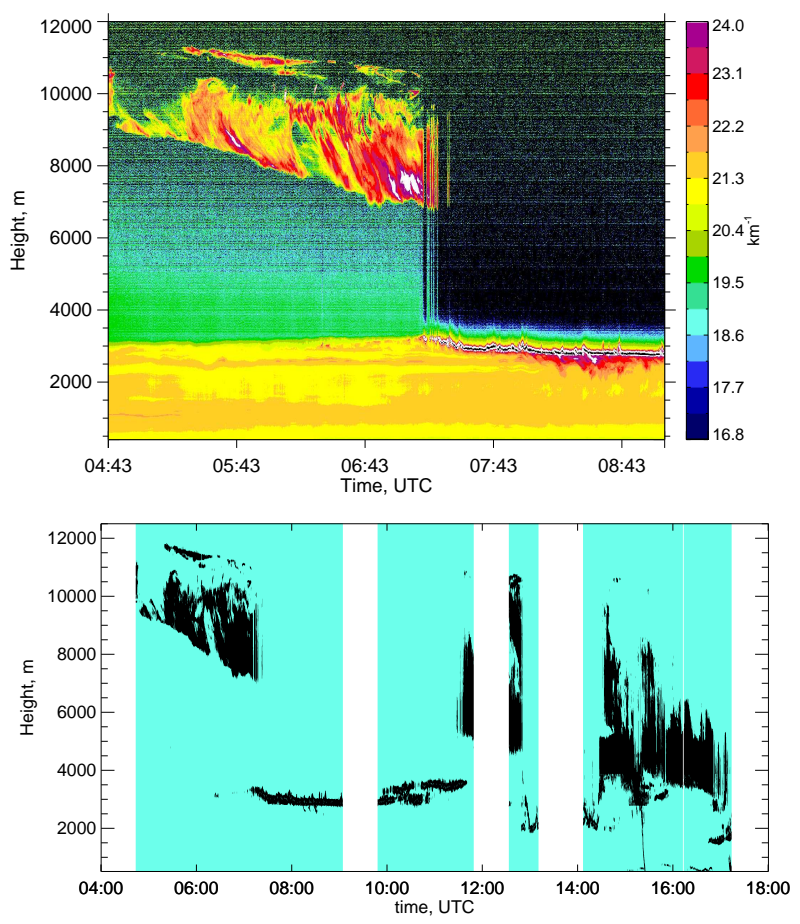

Fig. 4. Time-height cross-section of range-corrected backscatter signal (top) for a single limited measuring interval and derived cloud mask (bottom) for $14 \mathrm{~h}$ of 4 June 2004.

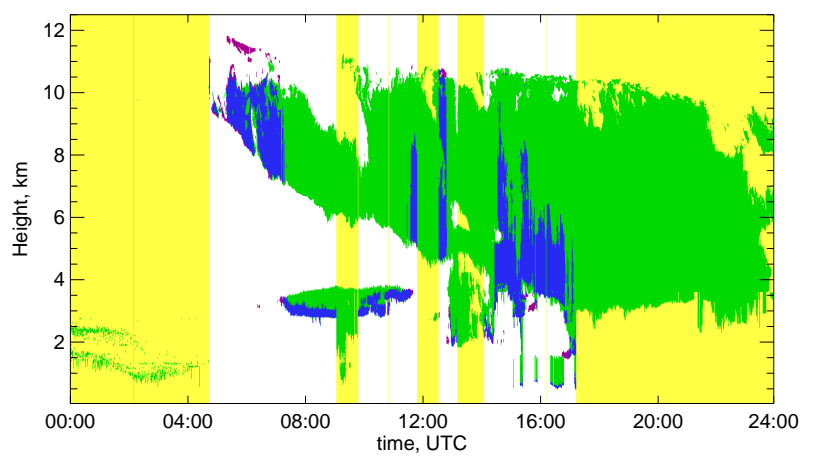

Fig. 5. Cloud mask derived from radar and lidar on 4 June 2004. Meaning of colors: yellow: no lidar observation, green: radar cloud, blue: radar and lidar cloud, purple: lidar cloud.

radar. Elevated cloud base heights agree well for both instruments.

The errors in the determination of the geometrical boundaries of clouds strongly depend on the height of the cloud bases and tops. High cirrus clouds above $10 \mathrm{~km}$ are only visible for the lidar. But lidar measurements are only available at $33 \%$ of all radar measurements and even in those periods 


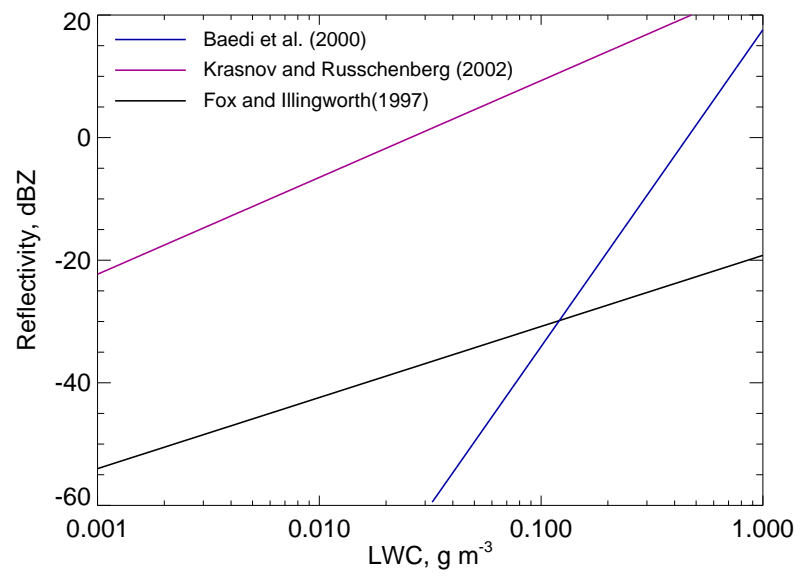

Fig. 6. Derivation of liquid cloud water content from cloud radar reflectivity by relations of LWC and $\mathrm{dBZ}$ from different authors, applied at different ranges of $\mathrm{dBZ}$.

the lidar beam is often blocked by low-level water clouds.

The rms-deviation of cloud base height as determined by the two lidar systems, DIAL and ceilometer, is about $100 \mathrm{~m}$ and characterises the uncertainty caused by the different retrieval algorithms. The error in the cloud base height determination by cloud radar is as small as the height resolution, i.e. $30 \mathrm{~m}$, but the cloud base may be not well defined The cloud cover, which was derived from these observations, is defined in Sect. 4.3.

\section{Water content of clouds}

The key parameter describing the role of clouds in the water cycle is - besides the geometrical size - their water content which is denoted here by $M$. It is determined by:

$M=\frac{\pi}{6} \rho \int_{0}^{\infty} N(D) D^{3} d D$

where $D$ is the dropsize, $N(D)$ is the dropsize distribution and $\rho$ is the water density. Unfortunately, $N(D)$ cannot be measured directly because

$Z=\int_{0}^{\infty} N(D) D^{6} d D$

Therefore $M$ is estimated from the Ka-Band radar measurements by using empirical $Z-M$ relations of the form:

$Z=a M^{b}$

where $a$ and $b$ are empirical constants.

These $Z-M$ relations were obtained from the independent determination of liquid water content (LWC) and radar reflectivity of known dropsize distributions. Dropsize distributions can be obtained from airborne probes, cloud physical

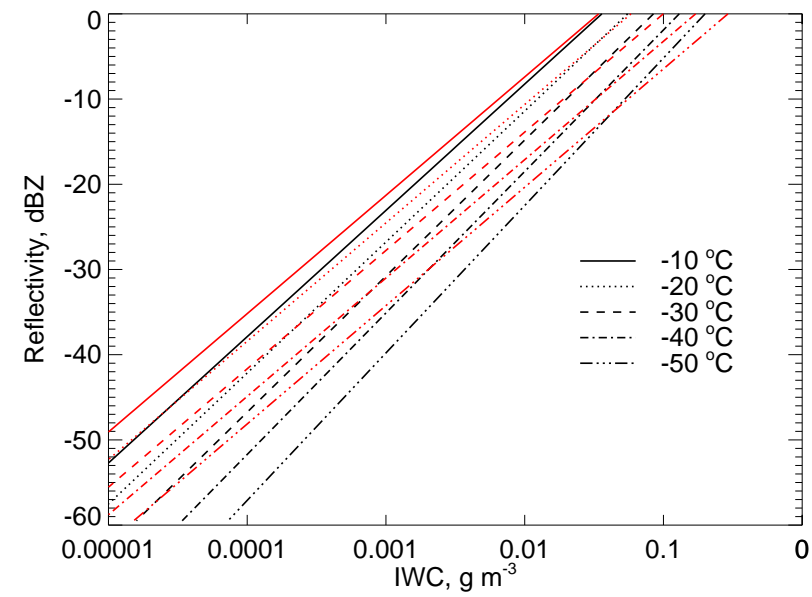

Fig. 7. Derivation of ice water content from cloud radar reflectivity by relations of IWC and dBZ according to Hogan et al. (2006), stratified by temperature, black lines: "best expected value", red lines: "best variance".

model calculations or the combination of remote sensing instruments (see e.g., Sauvageot and Omar, 1987).

A large problem deriving cloud water content is imposed by drizzle within water clouds. New attempts to take this effect into account use different $Z-M$ relations for clouds without drizzle, with a slight drizzle portion and with a large drizzle portion (see Fig. 6). According to a suggestion of Krasnov and Russchenberg (2003) these relations hold for certain dBZ-ranges which are also used in this study. For $\mathrm{dBZ}<-30$ the relation of Fox and Illingworth (1997), for $-30<\mathrm{dBZ}<-20$ the relation of Baedi et al. (2000), and for $\mathrm{dBZ}>-20$ the relation of Krasnov and Russchenberg (2002) is applied.

There exists a variety of algorithms to derive LWC from cloud radar data which differ mostly in the coefficients in Eq. (3). Advanced methods combine instruments like cloud radar, microwave radiometer and radiosonde or make use of multi-wavelength radar systemes (see e.g., Meywerk et al., 2005; Löhnert et al., 2004; Gaussiat et al., 2003). Krasnov and Russchenberg (2006) suggested the use of lidar-derived optical extinction to determine the optimum choice of parameters $a$ and $b$ in Eq. (3).

The ice water content of clouds (IWC) can be similarly calculated from a $Z-M$ relation (e.g., Sassen, 1987; Liu and Illingworth, 2000) with $M$ denoting IWC here. But since different ice crystal types which can be assigned to certain height - and thus temperature - ranges cause different reflectivity, a new $Z-M$ relation was suggested by Hogan et al. (2006). This algorithm stratifies the $Z-M$ relation with temperature and is illustrated in Fig. 7. Hogan et al. (2006) derive two different formulae for different aims, one formula seems to give best results for the expected value of IWC when com- 
pared with aircraft measurements (black lines), the other formula gives better agreement when comparing variances or PDFs of IWC (red lines).

Generally, the derivation of cloud water content from radar reflectivity suffers from several simplifying assumptions. Better algorithms to discriminate between water droplets and ice crystals make use of the reflectivity ratio of the radar and lidar systems (Tinel et al., 2005). In this study this method was not applied because of the low lidar availability particularly at high levels.

The accuracy of cloud radar-derived liquid water content and ice water content using $Z-M$ relations is nearly entirely determined by the validity of the assumptions of the applied methods. The liquid water determination only from reflectivity may - according to the situation - enclose large errors up to $\pm 10 \mathrm{dBM}$.

\subsubsection{Precipitation}

Precipitation measurements are continuously available from the PLUVIO network and from one MRR at Lindenberg. The general difficulty that point measurements are not necessarily representing the average inside a model grid box applies particularly to precipitation due to the extreme spatial heterogeneity of the precipitation field. In this study the network data are used for calculating area averages of rain rates, while the MRR data represent a single station. The results differ both in rain sum and in time structure (see below Fig. 21). The reason is that precipitation is strongly heterogeneous as e.g. shown for the measurement period in 2003 by Beyrich and Mengelkamp (2006). The MRR rain rates are nearly always smaller than those of the network. MRR point measurements have earlier been compared with a conventional rain gauge aside, and the $30 \mathrm{~min}$ averages deviate by approximately $20 \%$ (Peters et al., 2002).

\section{Regional model REMO}

The regional climate model REMO is a hydrostatic, threedimensional atmospheric model, that has been developed in the context of the Baltic Sea Experiment (BALTEX) at the Max-Planck-Institute for Meteorology in Hamburg, Germany. It is based on the Europa Model, the former numerical weather prediction model of the German Weather Service and is described in Jacob (2001) and Jacob et al. (2001). REMO uses the physical package of the global circulation model ECHAM4 (Roeckner et al., 1996; DKRZ, 1994) and can be run in forecast as well as in climate mode. Prognostic variables are the horizontal wind components, surface pressure, temperature, mixing ratio of water vapour and of cloud water.

The surface fluxes are determined by a bulk equation taking into account the difference of momentum, energy or water vapour at the surface and at the lowest model level.
The transfer coefficient consists of a neutral part and a stability function after Louis (1979). Surface evapotranspiration is composed of evaporation from the skin reservoir, bare soil, vegetation and snow (DKRZ, 1994). Soil moisture is - in contrast to soil temperature - determined at only one layer by a budget equation which includes evaporation, rainfall, surface runoff, drainage and snow melt (Dümenil and Todini, 1992). This type of scheme is called a "bucket model".

The vertical turbulent transport in the atmosphere is parameterised by a local diffusion equation. The diffusion coefficient is the product of the square root of the turbulent kinetic energy (TKE) and a length scale which is a prescribed length scale times a stability function. For TKE a prognostic equation is solved ("TKE-closure"). In the dry atmosphere no entrainment scheme is included. In this study the instantaneous latent heat flux in the atmosphere is recalculated from the diffusion coefficient and humidity profiles.

The height of the atmospheric boundary layer can be diagnosed from model output parameters or can be taken from the diffusion subroutine. This parameter is determined as the maximum value of two parameters,

$h_{b l}=\max \left(h_{d y n}, h_{c n v}\right)$,

the dynamical height

$h_{d y n}=0.5 \frac{u_{*}}{f}$

with $u_{*}$ : friction velocity and $f$ : Coriolis parameter and the convective height which is the height of the lowest level with a static stability larger than at the first level (DKRZ, 1994), a method which is often called "parcel method". The height of the convective boundary layer $h_{c n v}$ can also be determined as the height where the gradient of potential temperature or of absolute humidity or of TKE is largest. These methods refer to the definition of the CBL as a turbulent well-mixed layer with an inversion on top which restricts transport of matter to the CBL, see e.g. the discussion in Hennemuth and Lammert (2006). The CBL height values from different definitions mostly agree on undisturbed days with strong insolation while they may differ much on non-ideal days (see below, Fig. 12).

The simulation of clouds and precipitation in REMO is divided into the stratiform cloud and precipitation scheme accounting for clouds developing on scales that can be described directly by the prognostic variables of the model, and in the convective cloud and precipitation scheme for clouds on smaller scales. The stratiform cloud scheme in REMO, taken from the MPI Global Model ECHAM4, is based on the approach of Sundqvist (1978) and is described in detail in (DKRZ, 1994) and in Roeckner et al. (1996). In-cloud water $q_{c}$ is diagnosed assuming that the predicted cloud water mixing ratio $q_{w}$ is confined to the cloudy part of the gridbox. $q_{c}$ is then split into cloud ice water content (IWC) and cloud liquid water content (LWC) as a function of temperature following Rockel et al. (1991) (Fig. 8): above the melting point 
- here $0^{\circ} \mathrm{C}$ - the cloud consists entirely of liquid water while near $-50^{\circ} \mathrm{C}$ the cloud almost entirely consists of ice.

Convective clouds in REMO are parameterised using the Tiedtke mass flux scheme (Tiedtke, 1989) with some modifications following Nordeng (1994).

Total precipitation in REMO is the sum of precipitation formed in the stratiform cloud scheme and precipitation formed in the convective cloud scheme. Cloud cover is calculated as a nonlinear function of the grid-mean relative humidity.

\section{Quality assessment experiment}

\subsection{Site and time table}

The Meteorological Observatory Lindenberg of the German Weather Service is located $60 \mathrm{~km}$ southeast of Berlin (Neisser et al., 2002). The terrain is flat with gently rolling hills of less than $50 \mathrm{~m}$, and its hetereogeneous landscape of agriculture, forests, small lakes and villages is typical for the region and also for northern Central Europe.

The measurements took place in three time periods, 20 May 2003 to 14 June 2003, 11 May 2004 to 6 June 2004, and 26 August 2004 to 30 September 2004. The first campaign was the LITFASS-2003 campaign within the EVA_GRIPS project of the German Climate Research Program (DEKLIM) (Beyrich and Mengelkamp, 2006) aiming at the determination of area-averaged surface evaporation over a heterogeneous surface. LITFASS stands for Lindenberg Inhomogeneous Terrain - Fluxes between Atmosphere and Surface: a Long-term Study)

The comprehensive instrumentation at MOL, set up in order to characterise the vertical structure of the atmosphere includes energy balance stations (enhanced number during LITFASS-2003), a network of rain gauges, a ceilometer, a microwave cloud radar, and a Micro Rain Radar. Additional instruments during the three campaigns were a Differential Absorption Lidar (DIAL) and a Doppler lidar (operated by MPI for Meteorology).

Comparisons are performed for all three measuring periods. Only in case of a restricted availability of special data the period is shortened. The maximum number of $1 \mathrm{~h}$ values suitable for a model evaluation is 2400 but instrumental limitations often restrict this number considerably.

\subsection{Model runs}

In this study REMO was run in the forecast mode in order to simulate the atmospheric conditions at Lindenberg as close to the real weather as possible. This means that the model was initialized at 00:00 UTC and the forecast times from 07:00 UTC of the same day to 06:00 UTC of the following day were used. The horizontal resolution was $1 / 6^{\circ}$, i.e. approximately $18 \mathrm{~km}$. The model runs were nested in $1 / 2^{\circ}$ runs which were initialized and driven at the boundaries

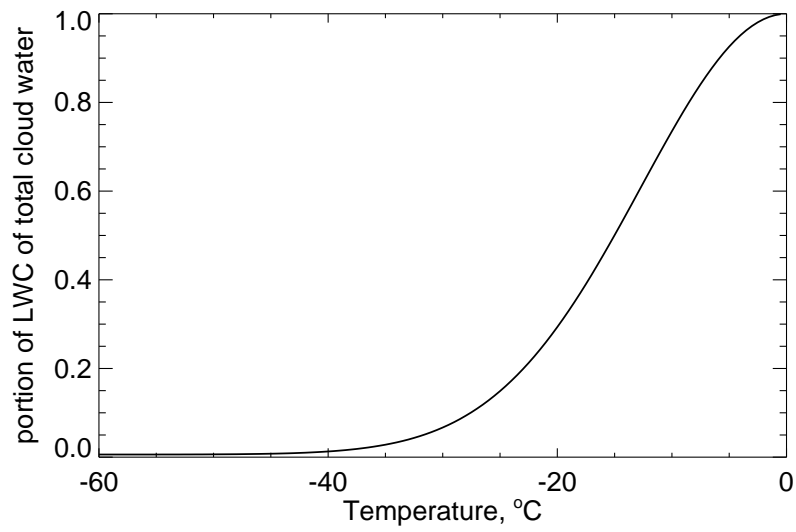

Fig. 8. Partitioning of predicted total cloud water into liquid cloud water and ice cloud water in REMO5.5.

with ECMWF analyses. Figure 9 shows the model domain of the $1 / 2^{\circ}$ runs and of the nested $1 / 6^{\circ}$ runs.

The water cycle parameters which are compared with observations are absolute humidity (calculated from mixing ratio and temperature), surface latent heat flux, soil wetness, water vapour transport in the atmosphere, cloud cover, cloud water content, and precipitation. Output parameters are available every $1 \mathrm{~h}$. Two different models levels are distinguished, full levels which characterise the centre of gravity of the model layers as well as half-levels which are the boundaries of the model layers. The model levels are transformed to pressure levels by means of the surface pressure value, and then the individual height of these levels is calculated using the barometric height equation. The predicted values are defined on full levels, for the comparison with observations they are regarded representative for the layer between the adjacent half levels.

\subsection{Transformation of observational data to model grid}

All vertical profiles of water cycle parameters - absolute humidity, cloud cover, cloud liquid water content and cloud ice water content - are transformed to the vertical grid of the model REMO with $\Delta \mathrm{z} \approx 35 \mathrm{~m}$ near the surface and $\Delta z \approx 1600 \mathrm{~m}$ at $10 \mathrm{~km}$. For vertical averaging the timedependent REMO level heights are averaged over all model runs. Table 2 shows that the standard deviation of the average level heights increases with increasing height and is larger that $100 \mathrm{~m}$ above $6000 \mathrm{~m}$. The observed profile data are averaged corresponding to the layers between the half levels.

Model parameters are representative for a certain horizontal and temporal scale and a corresponding averaging of the observations is accomplished by temporal averaging. Both observational and model parameters should cover comparable scales which ideally results in different averaging intervals for different wind speed as it is discussed by van Mei- 


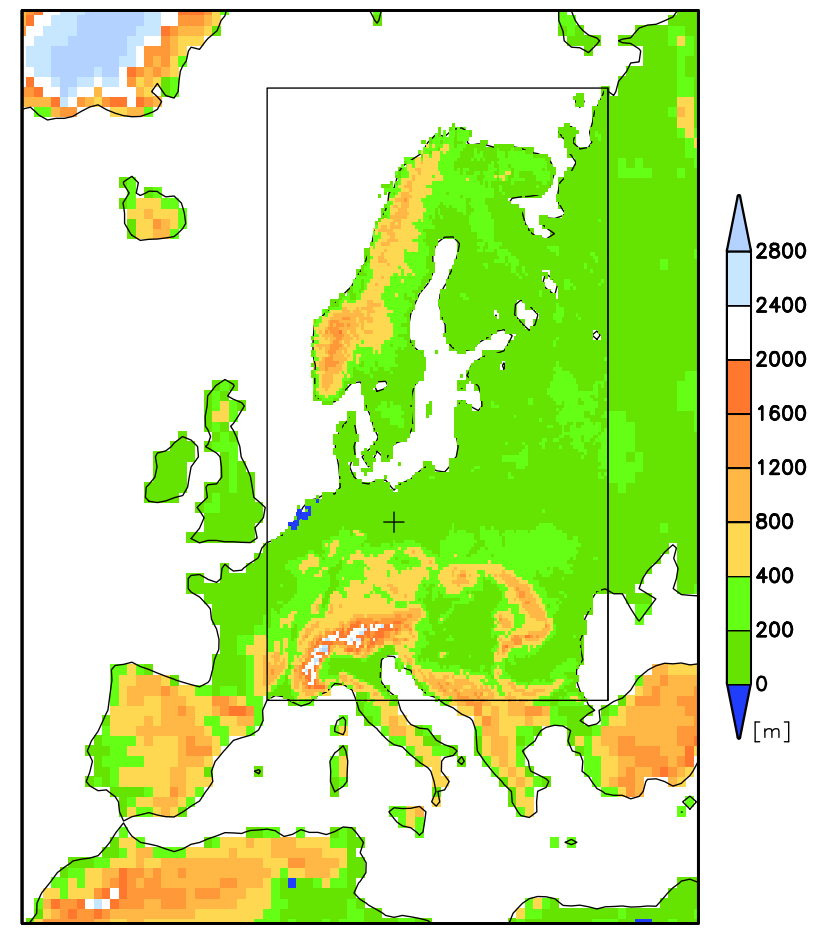

Fig. 9. Model domain of the $1 / 2^{\circ}$ and of the nested $1 / 6^{\circ}$ runs. The cross marks the position of Lindenberg.

jgaard and Crewell (2005). Moreover, the model output parameters characterize different model time intervals. Taking this into account, the measured humidity values are averaged over \pm 10 min around the model output times because they are compared with instantaneous model values. The boundary layer height is averaged over $\pm 15 \mathrm{~min}$ around the model output times because the values are strongly variable. Surface fluxes are averaged over $1 \mathrm{~h}$, precipitation is added up to $1 \mathrm{~h}$. The observed cloud cover is the percentage of cloud signals detected in height/time boxes with vertical extension equal to the respective REMO layer thickness and with $1 \mathrm{~h}$ duration corresponding to the REMO output time interval. Only data with more than $2 \%$ cloud cover are regarded as clouds. Cloud LWC and IWC are averaged over height and time of REMO grid boxes.

\subsection{Representativeness and comparability of data sets}

The two data sets of water cycle parameters - derived from observations and the model - differ in spatial and temporal representativity. Therefore, the comparability and its limitations should briefly be discussed.

Model parameters are partly instananeous values (humidity, cloud water content, soil wetness, and parameters derived from instantaneous parameters like cloud cover, soil wetness and atmospheric fluxes) and partly means or sums over $1 \mathrm{~h}$ (surface evaporation, precipitation). If possible, instanta-
Table 2. Average model level heights and standard deviation.

\begin{tabular}{rrrr}
\hline Height & std.dev. & height & std.dev. \\
\hline 17.35 & 0.48 & 2233.39 & 34.85 \\
51.90 & 0.85 & 2558.15 & 39.90 \\
105.67 & 1.66 & 2894.22 & 45.19 \\
179.47 & 2.81 & 3242.44 & 50.78 \\
271.23 & 4.24 & 3603.65 & 56.70 \\
381.40 & 5.99 & 3978.91 & 62.99 \\
493.11 & 7.74 & 4385.92 & 69.96 \\
605.98 & 9.51 & 4829.09 & 77.67 \\
742.43 & 11.65 & 5573.33 & 91.06 \\
903.82 & 14.16 & 6652.60 & 111.83 \\
1064.04 & 16.65 & 7778.39 & 134.29 \\
1222.59 & 19.11 & 9011.16 & 156.79 \\
1383.63 & 21.63 & 10451.21 & 172.27 \\
1564.53 & 24.46 & 12221.61 & 159.26 \\
1765.82 & 27.60 & 14631.70 & 118.97 \\
1970.81 & 30.77 & 18132.40 & 85.67 \\
\hline & & &
\end{tabular}

neous values are compared to observations of short averaging time (humidity, ABL height, see Sect. 4.3).

Simulated values are representative for the grid box or surface area defined by the horizontal model resolution. Additionally, the numeric calculation scheme introduces an uncertainty of at least one mesh size in each direction. The uncertainty can be estimated by the difference of neighbouring values to the selected gridbox and can be regarded as negligible in a rather uniform area like the Lindenberg area. Thus a height uncertainty of one vertical mesh size remains.

The accuracy of measurement-derived water cycle parameters is given in Sect. 2.2, but additional uncertainties arise from the transformation to the model grid. Height averaging over increasing intervals with increasing height and time avering over $1 \mathrm{~h}$ or shorter intervals smoothes small-scale features and thus improves the comparability with model values which are representative for a $300 \mathrm{~km}^{2}$ gridbox. But averaging may in the case of cloud cover lead to a larger portion of small cloud cover values. For surface values the use of area-averaged observations - e.g. from networks is highly recommended because surface heterogeneities are mostly large (Mengelkamp et al., 2006). Atmospheric heterogeneities are assumed to be smaller because of atmospheric mixing (Parlange et al., 1995). Generally, the statistical comparison is restricted to parameters which are not too much influenced by the different time and space resolution of model and observations.

Additionally, some observations suffer from conditional sampling errors as e.g. demonstrated by Protat et al. (2006). Lidar data are not available during precipitation periods and thus may lead to a biased comparison result. In the presented study the DIAL data are only used for comparative process studies and not for statistical comparisons. 
There exists a general problem in comparing observed and modelled clouds because the parameters are derived differently. Cloud boundaries and cloud cover are derived directly from measured radar and lidar reflectivity, but cloud liquid water and ice water content are diagnosed making certain assumptions. The opposite is the case for models, here total water content - in enhanced models liquid water content and ice water content - is predicted, but cloud cover is diagnosed from the predicted relative humidity. So in the comparison of cloud cover and liquid/ice water content one of the respective parameters is diagnosed using assumptions which may not be valid for all situations. This has to be kept in mind in the discussion of comparisons.

\section{Results of comparison}

5.1 Humidity field, boundary layer height, evaporation, soil moisture

The direct comparison of simulated and observed humidity fields in the lower troposphere shows that the diurnal evolution of the CBL is well reproduced in the model, although height of the boundary layer and humidity values do not always agree with observations.

For a statistical analysis the observed humidity field transformed to the REMO grid is used. The number of data pairs per gridbox - i.e. the number of observations - is 30 to 50 in the ABL below 1500 m and between 07:00 and 18:00 UTC, in the region above the boundary layer less observations are available because of cloud occurrences and limited range of the DIAL used in 2004 (Fig. 10). Statistical values are only calculated for grid boxes with more than 10 samples.

Simulated and observed humidity values are well correlated within the convective boundary layer below $1000 \mathrm{~m}$ and in the lower part of the free atmosphere (around $2000 \mathrm{~m}$ ) as Fig. 10, upper panel shows. In the lower height levels the correlation coefficient is larger than 0.75 , whereas in the layer between $1000 \mathrm{~m}$ and $2000 \mathrm{~m}$ the correlation coefficient is $0.4-0.7$. In this region observed values often lie within the CBL while simulated values lie above the CBL, as this is often too low in the model. A marked distinction between the layer below $1000 \mathrm{~m}$ and the layer between $1000 \mathrm{~m}$ and $2000 \mathrm{~m}$ is also reflected in the bias and the rms-error. While the humidity below $1000 \mathrm{~m}$ is strongly biased (modelobservation: 1.5 to $3 \mathrm{~g} \mathrm{~m}^{-3}$ ) but exhibits a low rms-error, the humidity above the CBL agrees well on average, but shows a large rms-error.

This difference is also manifest in statistics of humidity values from all grid boxes in the range of $500 \mathrm{~m}$ to $1000 \mathrm{~m}$ and $1000 \mathrm{~m}$ to $2000 \mathrm{~m}$. Data between 10:00 to 16:00 UTC are taken into account (Fig. 11).

The data in the lower range, i.e. in the CBL, are well correlated but are strongly biased. Whereas the data in the layer where the model often predicts free atmosphere show a large
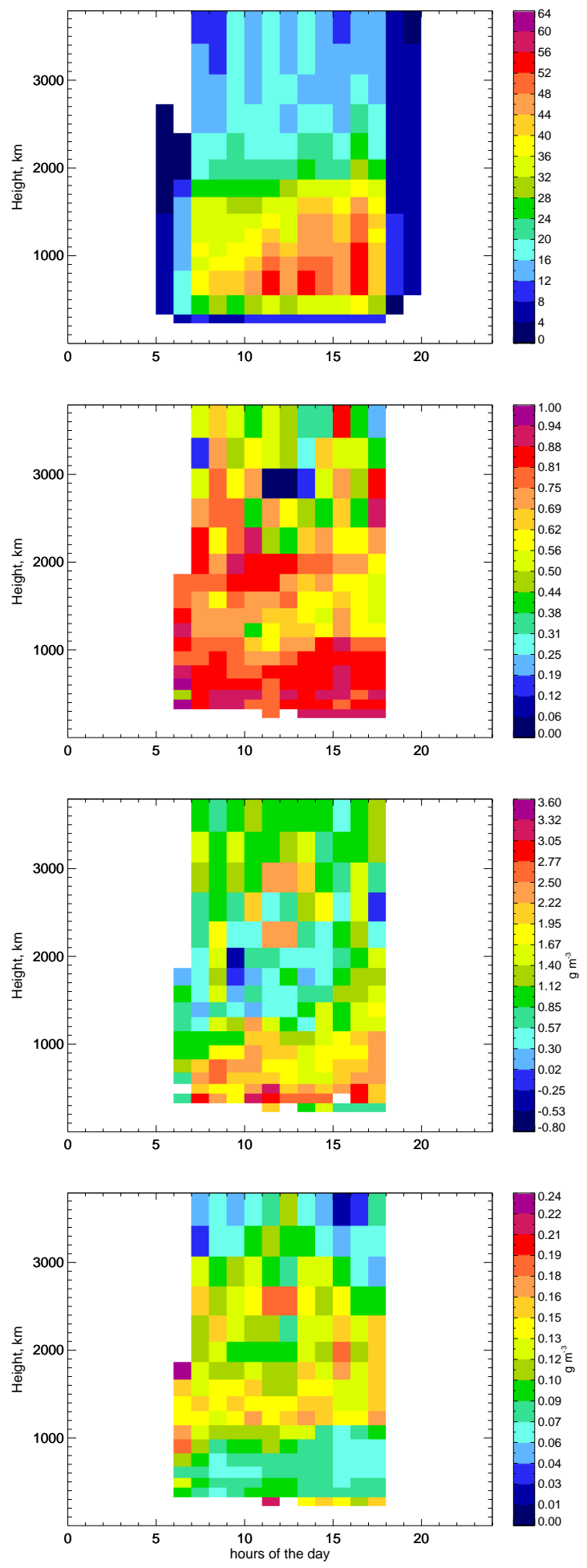

Fig. 10. Number of $1 \mathrm{~h}$ humidity observations in the Lindenberg gridbox, correlation coefficient, bias and rms-error of REMO humidity versus observed humidity. 

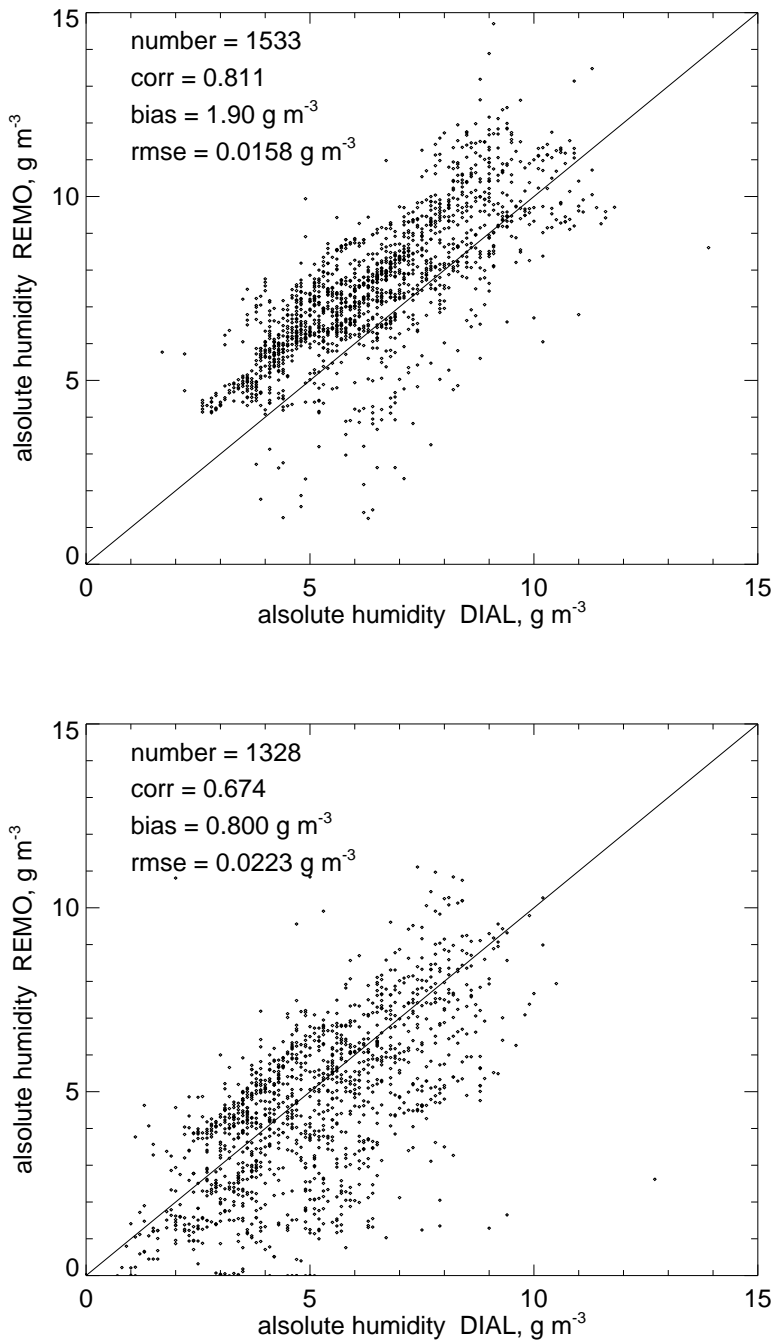

Fig. 11. Scatter plot of humidity values from REMO and observations, within the boundary layer (top), and above the boundary layer (bottom).

scatter, which results in a poor correlation and enhanced rmserror. The bias lies far beyond the measurement uncertainty.

Comparison of ABL height values derived from REMO and from DIAL backscatter confirms the assumption that the model derived ABL height is often too low. Figure 12 shows two examples of the time development of the ABL height. On 10 June 2003 the coincidence between all modelled and the observed ABL height is good although the observed maximum height of the CBL is approximately $500 \mathrm{~m}$ larger than the simulated height. The underestimation of the CBL height by REMO is more obvious on 7 June 2004. The latter example is from a day with boundary layer clouds and shows that the variability of the ABL height is large. The representation of boundary layer clouds in REMO will be discussed later in Sect. 5.3.
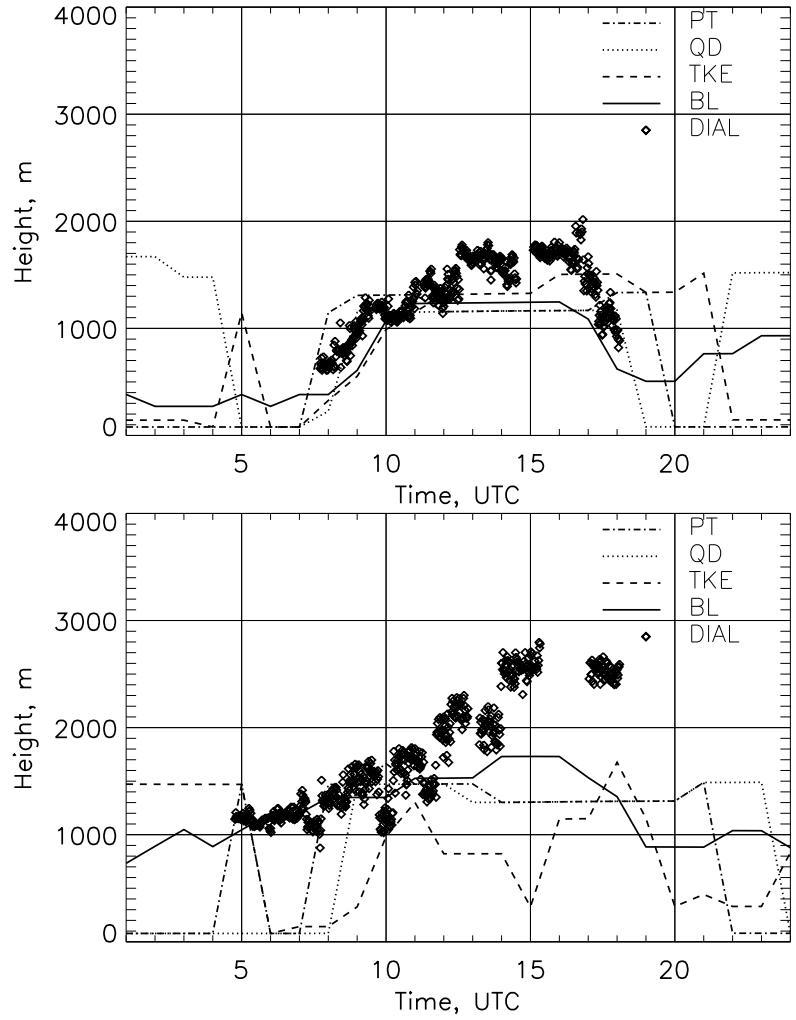

Fig. 12. ABL height derived from REMO and from DIAL on 10 June 2003 (top) and 7 June 2004 (bottom). The model ABL height is derived from the gradient of potential temperature (PT), of specific humidity (QD), of turbulent kinetic energy (TKE) and from static stability (BL, see Sect. 3).

Leaving out all days with a complex development like frontal passage, strong advective influences or breakdown of ABL height and regarding only the values between 10:00 and 16:00 UTC the scatter plots between the observed ABL height with the different REMO ABL heights show large deviations (Fig. 13 showing $h_{b l}$ ). The correlation coefficient between observed and different model-derived ABL heights is in the range of 0.28 (for the potential temperature gradient method) to 0.50 (for the parcel method). The observed ABL height covers a larger range of height values compared to the model ABL height. Even if an error of observed ABL height of $200 \mathrm{~m}$ and additionally the REMO height uncertainty of $160 \mathrm{~m}$ at $1000 \mathrm{~m}$ height is assumed it is obvious that most deviations are larger.

The lower panel of Fig. 13 shows the same relation, but only for undisturbed days after rain events. The agreement is much better, the correlation coefficient varies between 0.43 (for the TKE gradient method) and 0.80 (for the humidity gradient method and the parcel method). This confirms the ability of the model to well simulate situations with wet soils. 

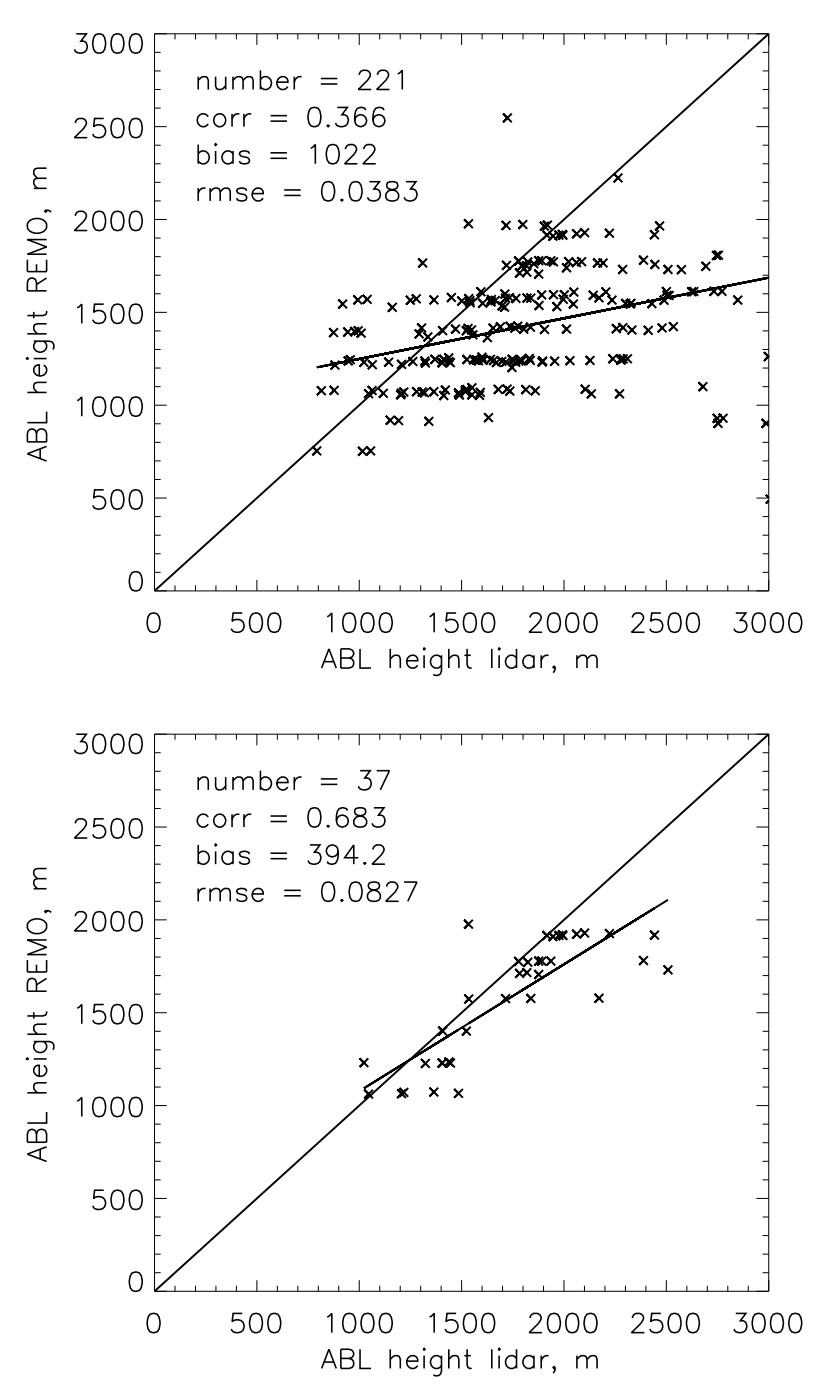

Fig. 13. ABL height derived from REMO (according to Eq. 4) and from DIAL and regression line. Top: for all undisturbed days, bottom: for undisturbed days after rain events.

The crucial parameters determining the humidity in the CBL and the height of the CBL are latent and sensible heat flux. They determine the amount of water supplied from the surface and control the growth of the $\mathrm{CBL}$ - together with the stratification of the free atmosphere and synoptic-scale subsidence (see e.g., Batchvarova and Gryning, 1994). During LITFASS-2003 there was the opportunity to compare REMO evaporation with an areal average of evaporation from a network of micrometeorological stations. Figure 14 shows time series of simulated and observed surface fluxes for a 12 day period.

The simulated latent heat flux is much larger than the observed one, the sensible heat flux is lower. There are only a few days on which the modelled latent heat flux is equal to or even smaller than the observed flux on 27 May, 31 May, 6 June, and 9 June. These are days with or after rain events
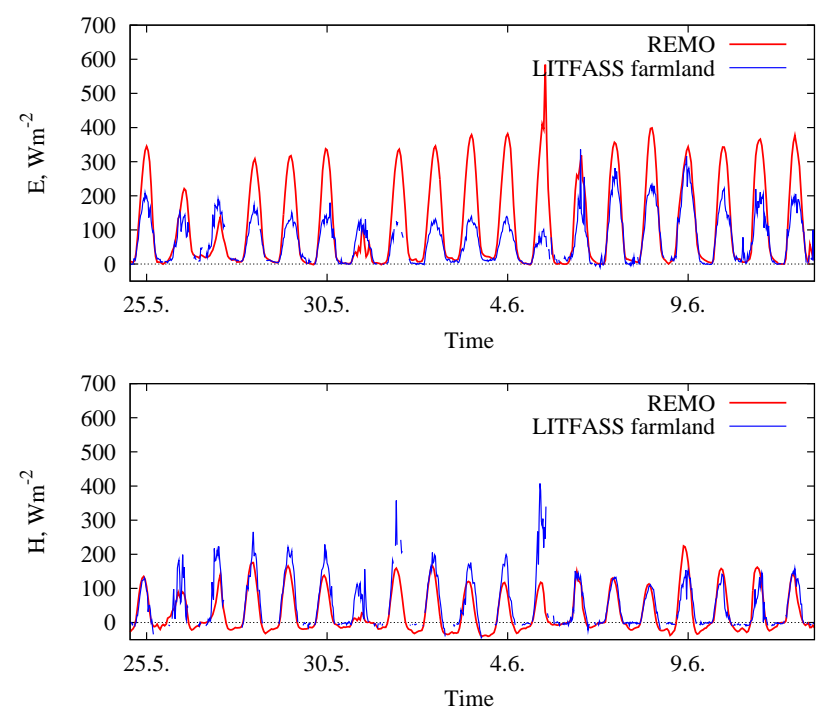

Fig. 14. Time series of surface latent heat flux (top) and sensible heat flux (bottom) from 1 to 12 June 2003.

with the consequence of a decreasing Bowen ratio. The deviations between modelled and measured fluxes is - at least for the latent heat flux - much larger than the measurement uncertainty of maximum $20 \%$ stated in Sect. 2.2.1, the agreement on wet days is within this range.

Since boundary layer processes are influenced by soil parameters we compare modelled and observed soil moisture. A direct comparison of simulated and observed soil moisture is difficult because REMO has a one layer scheme and the measurements comprise several soil layers. The measured soil moisture is given in volume percentage and the simulated soil moisture is soil water content in $\mathrm{m}$. So the time series are only being compared qualitatively here. Figure 15 shows the evolution of observed and simulated soil moisture during LITFASS-2003. It is obvious that during dry periods the soil moisture decreases steadily in all depths, and after rain events the upper layers are moistened. The simple "bucket"-model of REMO shows decreasing soil wetness and only little reaction to rain events. The large increase in soil moisture in the upper $10 \mathrm{~cm}$ which dominates evapotranspiration cannot be simulated by the one layer scheme. The deviation between observation and simulation relates to the missing vertical structure of soil moisture. Error ranges cannot be supplied.

\subsection{Vertical water vapour transport}

Within the convective boundary layer water vapour is transported vertically by turbulent and convective eddies. The surface is generally a source of water vapour and evapotranspiration increases the water vapour amout in the boundary layer. Entrainment of air from the free atmosphere into the 

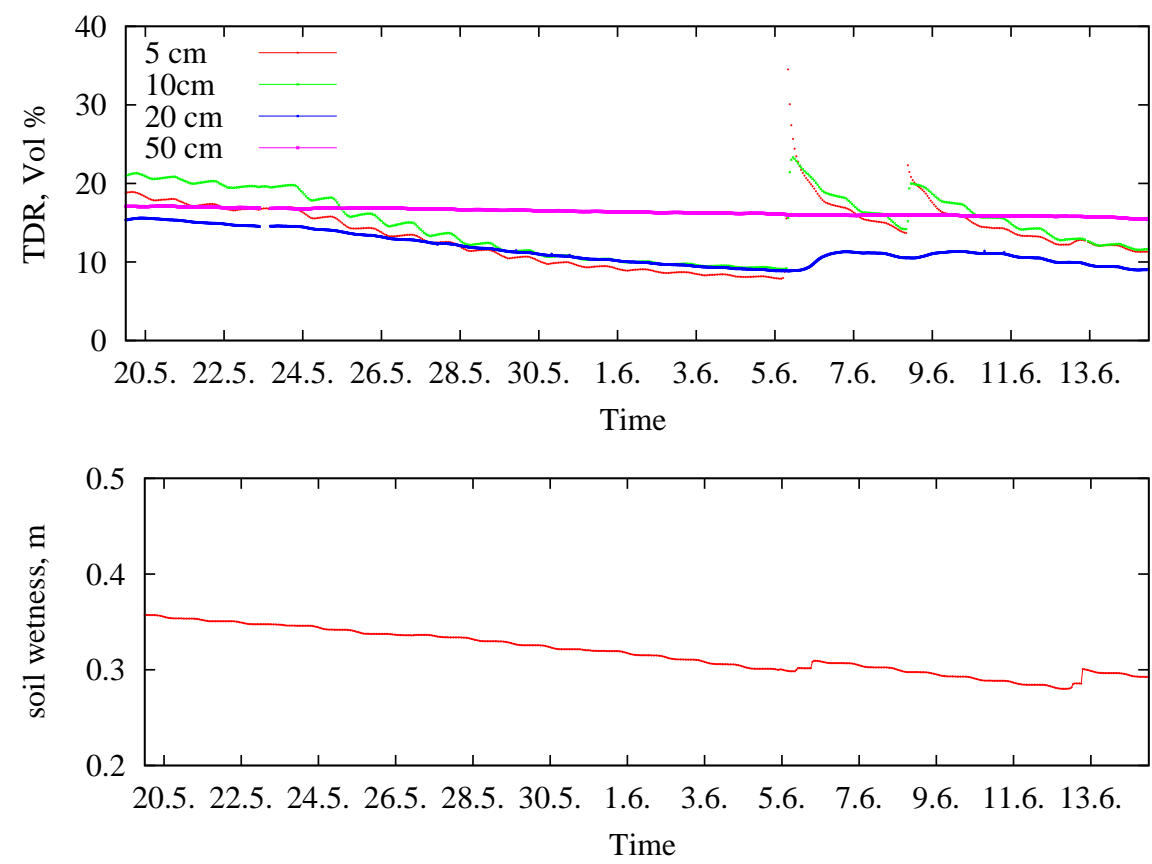

Fig. 15. Time series of observed (top) and simulated (bottom) soil moisture during LITFASS-2003. Note the different units of soil moisture, for explanation see text.

boundary layer occurs during the growth of the CBL (Stull, 1988). This is in most cases a downward flux of dry air. In situations with moist air advected over the ABL or with the CBL growing in the humid residual layer the entrainment flux may also be near zero. The top-down and bottom-up processes control the humidity profiles in structure and amount (Mahrt, 1976).

The measured and simulated flux profiles are only compared qualitatively, because the surface values differ a lot (see Sect. 5.1). The simulations mostly show a large positive entrainment flux in the morning connected with the CBL growth and after reaching a nearly constant CBL height either a slightly increasing or a slightly decreasing flux profile with height.

The flux magnitude is determined by the surface flux. Details of the profiles should be looked at with caution bearing in mind that the model flux is re-calculated with instantaneous output values while the observed flux is a time average over turbulent fluctuations. The simulations mostly show a large positive entrainment flux in the morning connected with the CBL growth and after reaching a nearly constant CBL height either a slightly increasing or a slightly decreasing flux profile with height.

Figure 16 presents latent heat flux profiles for two days with different characterics. On 30 May 2003 a large entrainment flux is observed during the period of growing CBL. On 9 June 2003 the flux is nearly constant with height in the
CBL and decreases at its top. This general structure remains even when accounting for the accuracy of the observations which is about $\pm 50 \mathrm{Wm}^{-2}$. The simulated flux profiles also show these features: increasing flux with height on 30 May and slightly decreasing flux with height on 9 June. But since the environmental conditions differ there are also differences in water vapour transport. On 30 June the CBL is steadily growing with large entrainment of dry air. The model CBL remains shallow and the entrainment stops after reaching the final height extent. On 9 June no entrainment flux is observed in the morning because the residual layer is humid, but the simulations show a large entrainment of dry air in the morning.

Generally, the observed profiles of latent heat flux often exhibit a decrease with height in the lower part of the CBL and - in case of entrainment of dry air - an increase towards the top of the CBL. This tendency cannot be found in simulated flux profiles which steadily increase or decrease with height throughout the CBL.

\subsection{Cloud amount}

Simulated and observed clouds are compared in a two-fold way, the occurrence of a cloud in the gridbox is considered as well as the cloud cover. Figure 17 shows cloud cover on three days with clouds in several layers. The first impression is that the model predicts too few clouds at all levels except above 

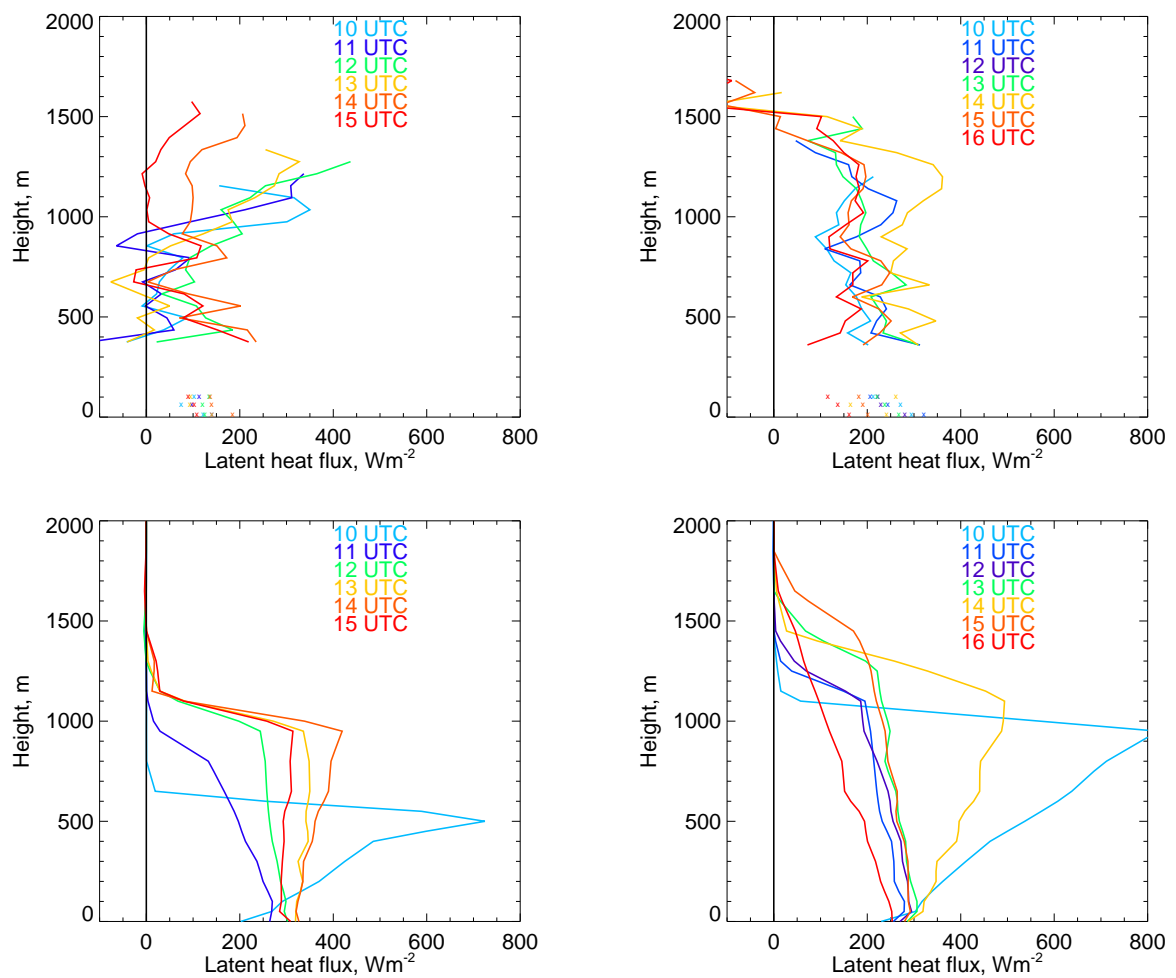

Fig. 16. Vertical profiles of latent heat flux on 30 May 2003 (left), and 9 June 2003 (right). Top: lidar measurements, bottom: REMO simulations.

$10 \mathrm{~km}$ height, and that the predicted cloud cover is mostly less than the observed one.

For a statistical analysis the number of cloud occurrences is counted for each height level and the cloud cover is added up. The total number of analysed $1 \mathrm{~h}$-samples is 1440 . The profiles are shown in Fig. 18. Both observations and simulations show two maxima of cloud occurrence and cloud cover, one maximum around $2000 \mathrm{~m}$ and a second maximum between $9000 \mathrm{~m}$ and $11000 \mathrm{~m}$. The mid-level region around $5000 \mathrm{~m}$ exhibits a distinct minimum of clouds. This structure of cloud occurrence is typical for mid-European climate and reported by e.g. Hogan et al. (2001), Brooks et al. (2004), Willén et al. (2005). It is obvious that in most height levels nearly twice as many clouds are observed than simulated. The same is true for the cloud cover sum. The opposite tendency can be seen for high-level clouds. Above $11 \mathrm{~km}$ the same number of clouds is observed and modelled, but the corresponding cloud cover is smaller in observations than in the model. Similar results are found in other sudies, e.g. for Europe by Hogan et al. (2001) and by Sengupta et al. (2004) for the ARM site in the southern Great Plains (USA).

The cloud observations, mainly based on cloud radar data, may still contain some non-cloud echos (compare Sect. 2.2.5). Most of these remaining echos are blinded when transforming the cloud mask to the grid where only averages larger than $2 \%$ are retained (see Sect. 4.3). Excluding all cloud observations with cloud cover smaller than 0.2 yields a better agreement with the number of simulated clouds at low and mid levels. But the tendency of the model to underestimate the number of low-level and mid-level clouds remains. As discussed in Sect. 4.4 the quantity cloud cover is determined in different ways from modelled and observed values - with cloud cover being directly derived from observations - and obviously the results differ strongly. For high-level clouds above $10 \mathrm{~km}$ the observational data are not of sufficient reliability to assess the quality of model cloud data (compare Sect. 2.2.5). The observed cloud amount is biased and a quantitative comparison is not possible.

An analysis of observed and simulated clouds for different times of the day and heights is shown in Table 3. Here we regard all cloud observations. Cloud occurrence and cloud cover are counted for cloud levels $0 \mathrm{~m}$ to $3000 \mathrm{~m}$ (low), $3000 \mathrm{~m}$ to $6000 \mathrm{~m}$ (mid), and $>6000 \mathrm{~m}$ (high) and for time periods 04:00 UTC to 09:00 UTC (morning), 10:00 UTC to 15:00 UTC (noon), 16:00 UTC to 21:00 UTC (evening), and 22:00 UTC to 03:00 UTC (night).

The Table shows that REMO predicts too few clouds at all times and heights with one exception of night-time high-level clouds. Generally, the agreement is best at night and for highlevel clouds. The largest differences between observed and 

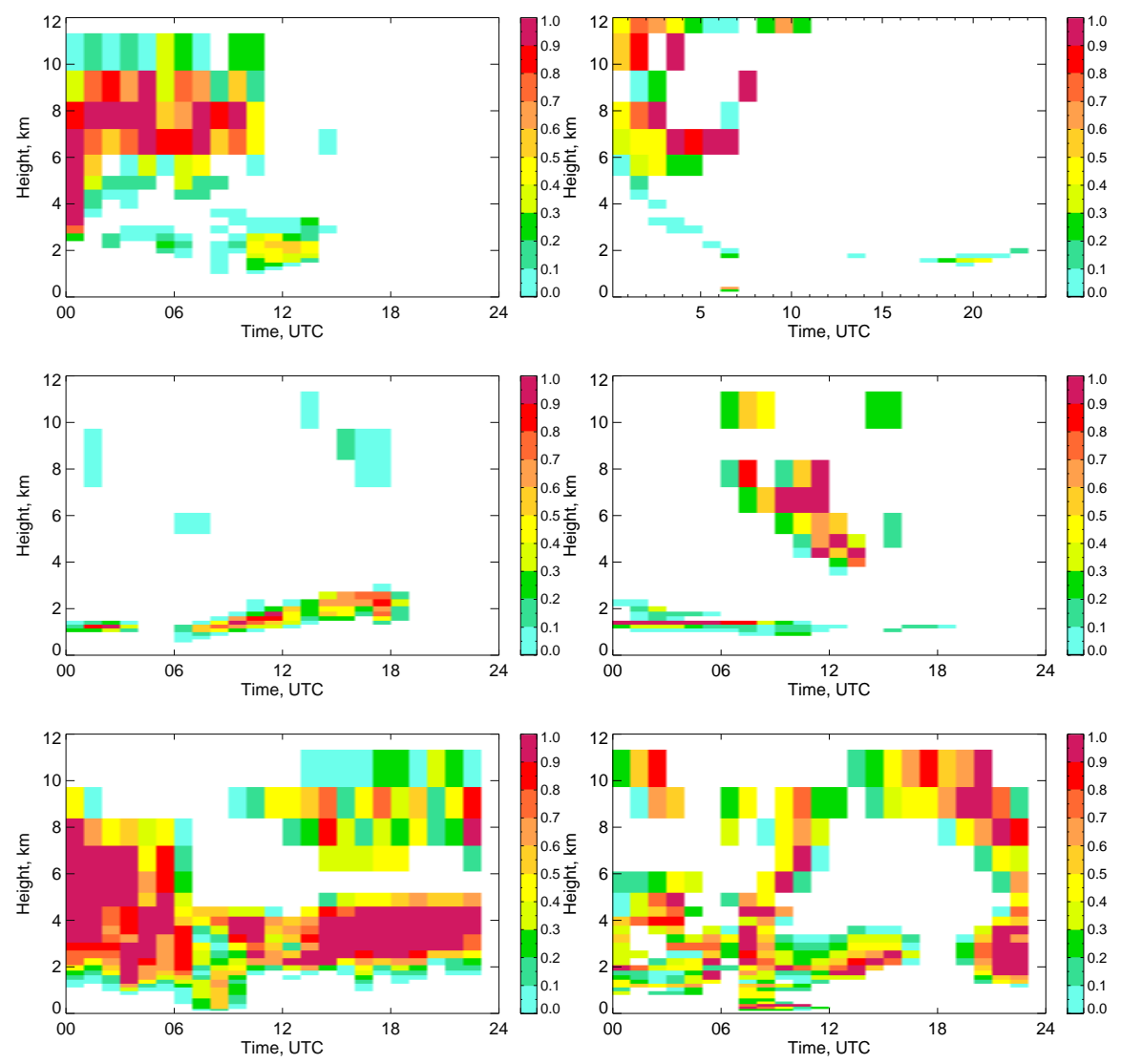

Fig. 17. Cloud cover on 11 June 2003 (top), on 8 June 2004 (middle), and on 7 June 2004 (bottom). Left: observation, right: REMO.

simulated cloud occurrence are found for low-level clouds in the morning and around noon. This kind of cloud is typically fair-weather convective boundary layer cloud. The sum over cloud cover confirms these results.

The observations show that boundary layer clouds extend over several grid levels whereas model ABL clouds are often restricted to one, two or three layers. Moreover, simulated boundary layer cloud bases are lower than observed ones. A typical case is shown in Fig. 17 (middle panels). For this day the Figs. 12 and 2 make clear that there is a broad entrainment layer of several $100 \mathrm{~m}$ with scattered clouds. The model does not show such a broad cloud layer. Regarding statistical values, the height of the average maximum of observed cloud occurrence is $1760 \mathrm{~m}$ and $1380 \mathrm{~m}$ for simulated clouds. The peak width at half-height to the upper minimum is $1500 \mathrm{~m}$ for observed, and $900 \mathrm{~m}$ for simulated clouds.

While cloud amount and cloud cover differ between observations and simulations the number of cloud levels is quite similar (Table 4). There is a tendency for REMO to produce slightly more cloud levels than observed. This is particularly the case when compact clouds are observed which extend over nearly the whole troposphere and the model separates the cloud into several layers (see Fig. 17, lower panels).

\subsection{Water content of clouds}

The total cloud water content of clouds consists of liquid water and ice water. Over a wide temperature range the clouds contain both droplets and ice crystals which is expressed in the model by the function determining the portions of LWC and IWC by temperature (see Fig. 8). But the determination of LWC and IWC in mixed clouds from radar reflectivity demands the partitioning of the reflectivity which is a difficult task requiring the solution of not well established empirical non-linear equations. So for this study only those clouds are compared for which the assumption of mainly water clouds or mainly ice clouds holds. This is determined by use of the REMO temperature values. Water clouds are supposed to occur below $3000 \mathrm{~m}$ where on most days temperature is above $2^{\circ} \mathrm{C}$. Only cloud radar data which are masked by ceilometer data are used. But additionally, the lower region up to $1800 \mathrm{~m}$ is excluded because of the problems with remaining non-cloud echos in radar reflectivity. The number of observed clouds in this layer is 2760 , the number of simulated clouds only 790 because many of the model ABL clouds appear below $2000 \mathrm{~m}$. Ice clouds are assumed to be in the region above $7000 \mathrm{~m}$ where temperature values below 

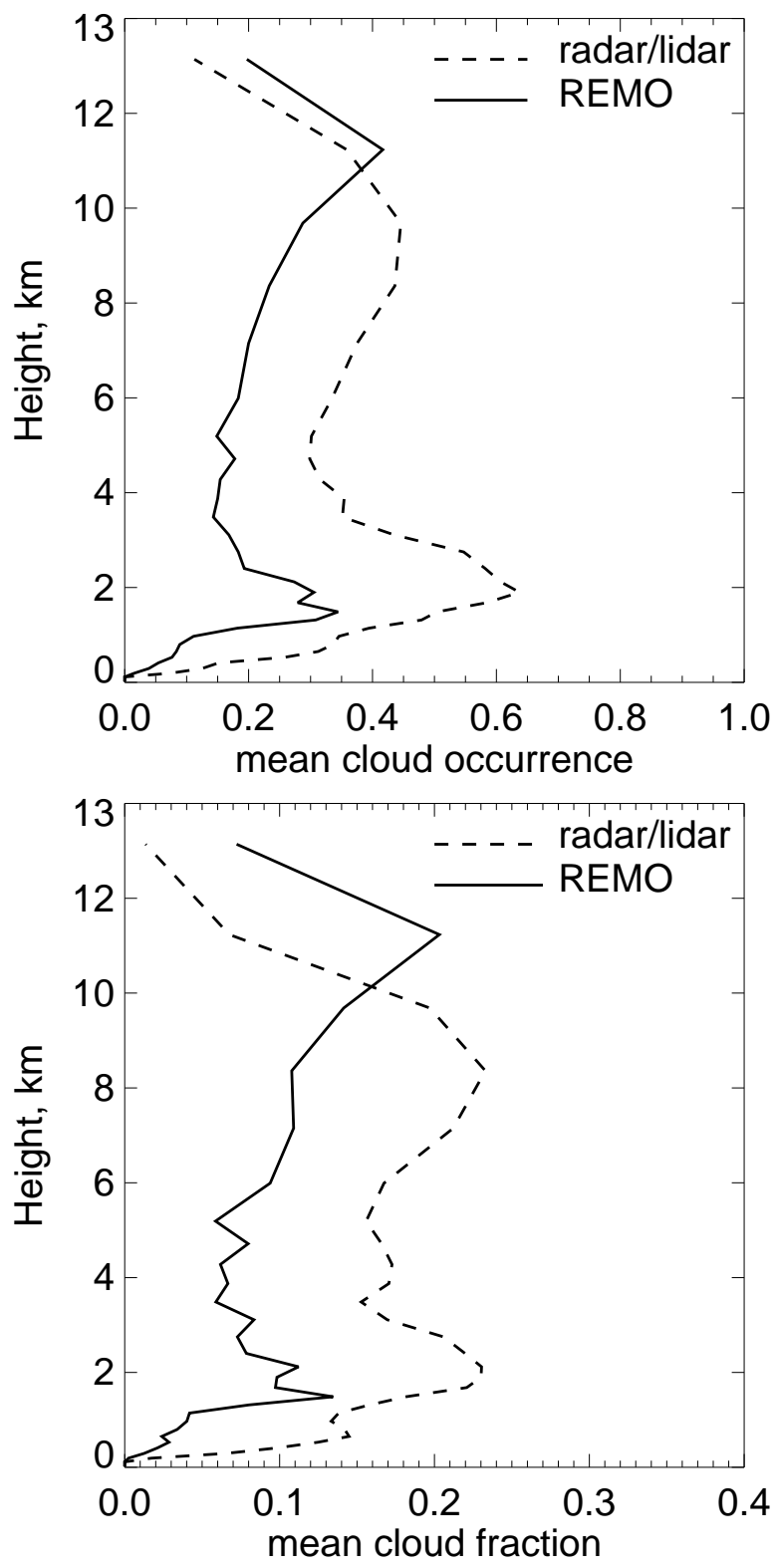

Fig. 18. Number of clouds (upper) and sum of cloud cover (lower).

$-30^{\circ} \mathrm{C}$ prevail. According to the temperature - IWC relation (Fig. 8) only less than $7 \%$ of the cloud water is liquid water. The number of model ice clouds for the comparison is 545 while the number of observed ice clouds is 683 . For both regions the observation-derived LWC and IWC, respectively, are compared with REMO total cloud water.

\subsubsection{Liquid water content}

Figure 19 shows the frequency distributions of simulated and observation-derived LWC in supposedly water clouds. The distribution of simulated LWC has a peak between $10^{-1}$ and
Table 3. Sum of cloud amount and cloud cover from observations and simulations for different height layers and time periods. For the definition of the classification scheme see text.

\begin{tabular}{|c|c|c|c|c|}
\hline Observation: & morning & noon & evening & night \\
\hline \multicolumn{5}{|c|}{ no of cloud occurrence } \\
\hline low & 1493 & 1512 & 728 & 856 \\
\hline middle & 356 & 387 & 408 & 257 \\
\hline high & 313 & 372 & 322 & 237 \\
\hline \multicolumn{5}{|c|}{ sum of cloud cover } \\
\hline low & 605 & 545 & 251 & 384 \\
\hline middle & 145 & 197 & 243 & 124 \\
\hline high & 102 & 168 & 144 & 106 \\
\hline REMO: & morning & noon & evening & night \\
\hline \multicolumn{5}{|c|}{ no of cloud occurrence } \\
\hline low & 592 & 403 & 402 & 551 \\
\hline middle & 158 & 163 & 181 & 187 \\
\hline high & 235 & 252 & 240 & 234 \\
\hline \multicolumn{5}{|c|}{ sum of cloud cover } \\
\hline low & 235 & 116 & 105 & 235 \\
\hline middle & 67 & 79 & 77 & 77 \\
\hline high & 104 & 117 & 124 & 109 \\
\hline
\end{tabular}

Table 4. Relative frequency of cloud levels from observations and REMO.

\begin{tabular}{lcccccc}
\hline system & \multicolumn{7}{c}{ number of levels } \\
& 1 & 2 & 3 & 4 & 5 & 6 \\
\hline radar-lidar & 0.645 & 0.286 & 0.058 & 0.009 & 0.001 & 0.000 \\
REMO & 0.591 & 0.289 & 0.083 & 0.031 & 0.004 & 0.001 \\
\hline
\end{tabular}

$10^{-2} \mathrm{~g} \mathrm{~m}^{-3}$ and there are no values larger than approximately $0.25 \mathrm{~g} \mathrm{~m}^{-3}$. Values smaller than $10^{-3} \mathrm{~g} \mathrm{~m}^{-3}$ occur rarely.

The frequency distribution of LWC from cloud radar data covers the range between $10^{-3}$ and $1 \mathrm{~g} \mathrm{~m}^{-3}$ with a nearly constant frequency between $10^{-3}$ and $10^{-1} \mathrm{~g} \mathrm{~m}^{-3}$ with a maximum near $1 \mathrm{~g} \mathrm{~m}^{-3}$. This peak is probably an artefact of the cloud radar data due to the inadequate treatment of drizzle droplets in the clouds. We also find a cut-off of values smaller than $10^{-3} \mathrm{~g} \mathrm{~m}^{-3}$ which may be due to the noise characteristics of the cloud radar.

The superimposition of an artificial peak and the cut-off at small LWC values falsifies the LWC distribution and makes the accurate quality assessment of model LWC impossible. As mentioned in Sect. 2.2.5 the LWC derived from cloud radar data is afflicted with problems and obviously the results are not plausible. Another reason for the the poor qua- 


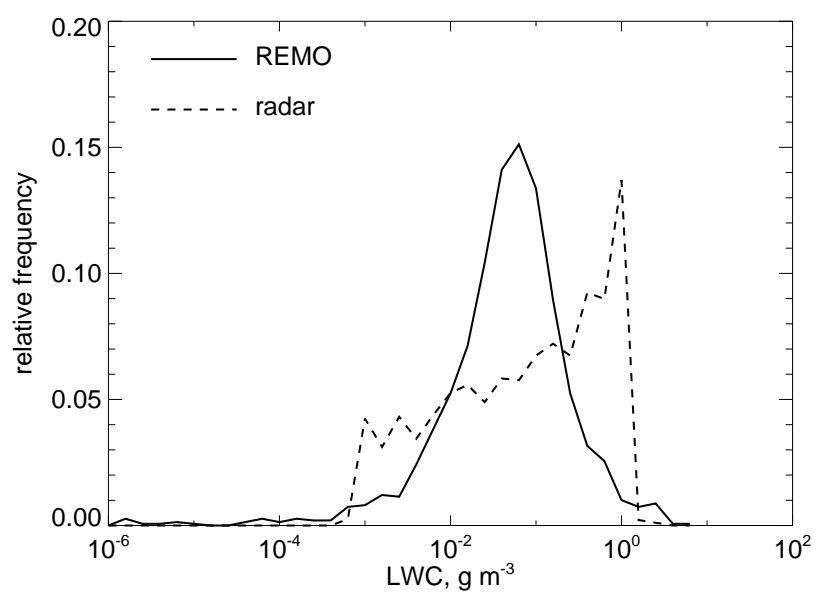

Fig. 19. Frequency distributions of LWC derived from REMO and from cloud radar (using the algorithm of Krasnov and Russchenberg (2003)) in the height range of $1800 \mathrm{~m}$ to $3000 \mathrm{~m}$.

lity of the radar retrieval of LWC may be related to the systematic difference (although depending on the cloud type) between radar observations of reflectivity factor $Z$ and the aircraft/balloon predictions of the same quantity, which was reported by Russchenberg et al. (2004).

\subsubsection{Ice water content}

The agreement of frequency distributions of IWC derived from the model and the cloud radar is better (Fig. 20). The radar-derived IWC is calculated according to the two algorithms given by Hogan et al. (2006) (see Fig. 7) and marked in Fig. 20 by "radar e" for best obtaining the expected value and "radar v" for best obtaining the variance.

The distributions cover the IWC range between $10^{-7}$ and $10^{-2} \mathrm{~g} \mathrm{~m}^{-3}$ with a maximum around $10^{-4} \mathrm{~g} \mathrm{~m}^{-3}$ and negative skewness. The REMO IWC distribution exhibits a narrower shape, it agrees with the radar IWC at large IWC values, the maximum is situated between $10^{-4}$ and $10^{-3} \mathrm{~g} \mathrm{~m}^{-3}$, but small IWC $\left(<10^{-6} \mathrm{~g} \mathrm{~m}^{-3}\right)$ values are missing. This is also evident in similar comparisons - with the mesoscale version of the Met Office Unified model - in the moderate temperature range of $-15^{\circ} \mathrm{C}$ to $-30^{\circ} \mathrm{C}$ shown by Hogan et al. (2006). A reason for the missing small model IWC values may be the threshold of $80 \%$ relative humidity in the gridbox for the formation of clouds. A lower threshold value would probably favorite a larger amount of small IWC.

In this particular comparison the model IWC distribution fits better with the IWC distribution of "radar e" than of "radar v" for large IWC values.

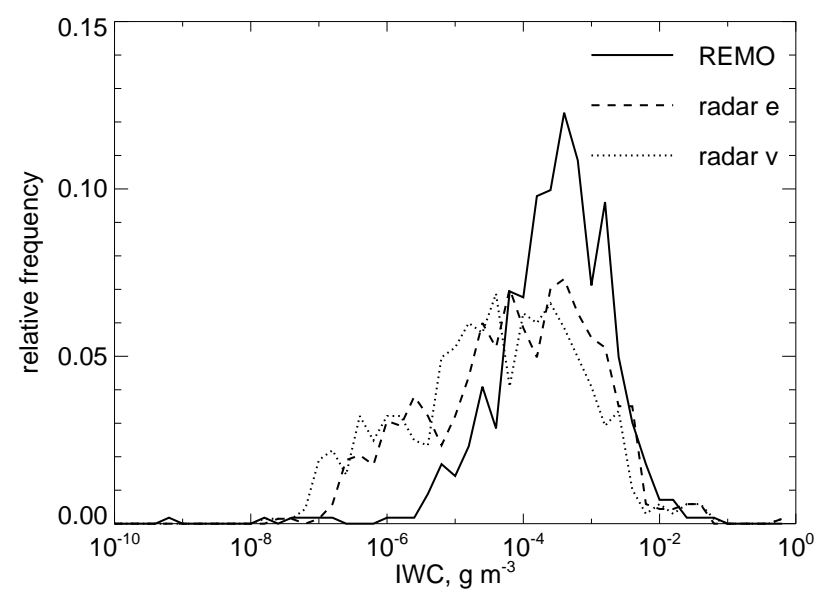

Fig. 20. Probability density functions of IWC derived from REMO and from cloud radar (using the algorithm of Hogan et al. (2006)) in the range of $6000 \mathrm{~m}$ to $10000 \mathrm{~m}$. The abbreviations "e" and " $\mathrm{v}$ " stand for the $Z-I W C$ - algorithms optimizing the expected value and the variance of IWC, respectively.

\subsection{Precipitation}

Precipitation is the parameter with the largest spatial and temporal heterogeneity and therefore difficult to compare for one gridbox and time periods of weeks. One of the three measuring periods - LITFASS-2003 period - was exceptionally dry and is therefore excluded in this comparison. Figure 21 shows time series of rainrates for the two campaigns of 2004 determined from the Micro Rain Radar, a network of conventional rain gauges and from REMO.

The precipitation predicted by the model captures most of the observed rain events in the Lindenberg gridbox, but some events are either not simulated or not observed. The total rain sums over the two periods in 2004 which are listed in Table 5 show a rather good agreement of simulated and observed rain. The sum lies within the measurement uncertainty of $20 \%$ and within a certainly larger error range due to limited representativity. The network rain sum is larger than the point measurement and better matches the REMO values.

Not only the total rain amount but also the frequency distributions are quite similar (see Fig. 22). The wellknown large frequency of very small rain rates - between 0 and $0.1 \mathrm{~mm} / \mathrm{h}$ - in the model is obvious, but also the area-averaged rain rate from the PLUVIO network shows a larger frequency of small rain rates than the single instrument MRR.

\section{Discussion and conclusions}

Several water cycle parameters in the atmospheric column over Lindenberg, at the surface and in the soil as observed 

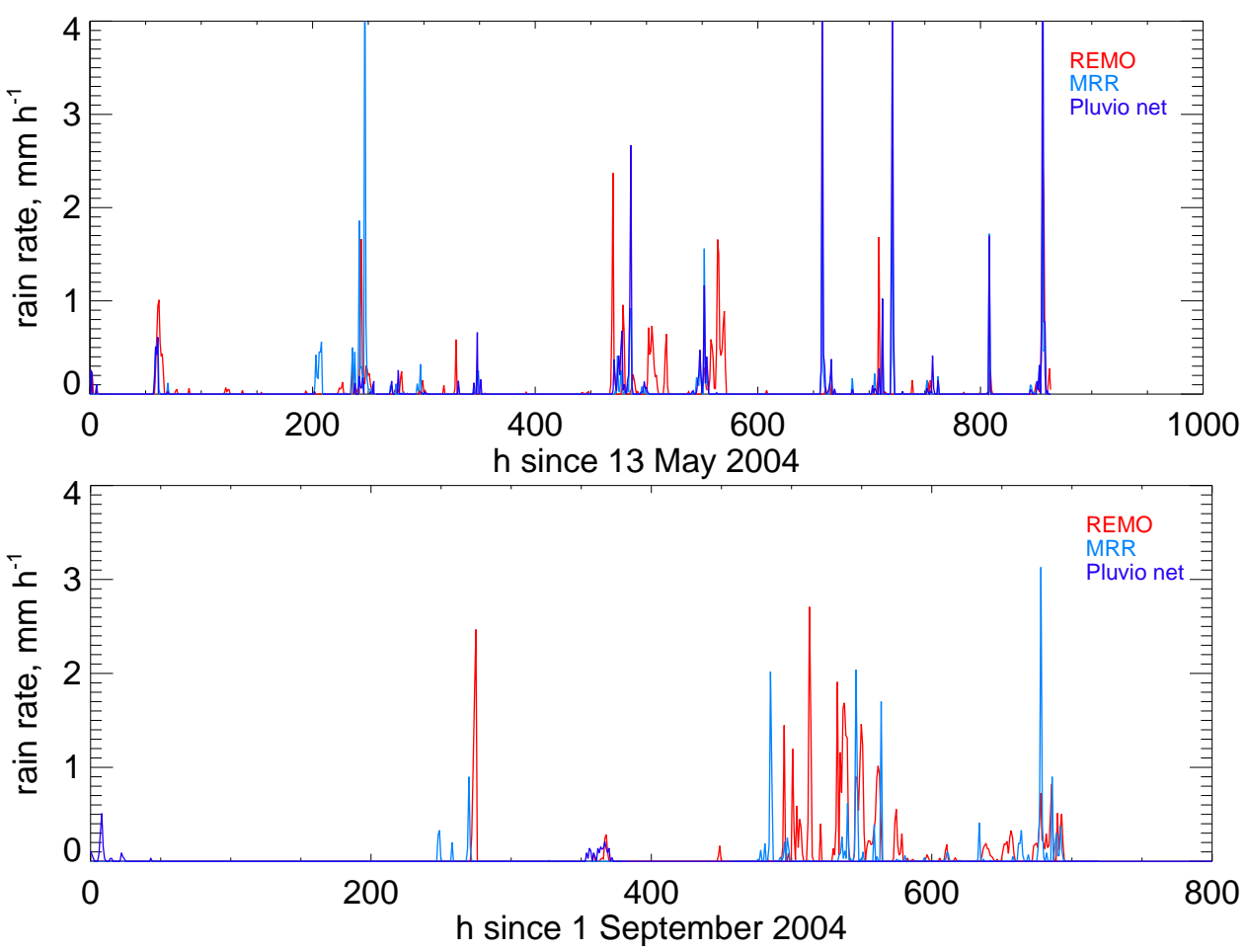

Fig. 21. Time series of rain rates for two measuring campaigns from REMO (red), MRR (light blue), and rain gauge network (blue).

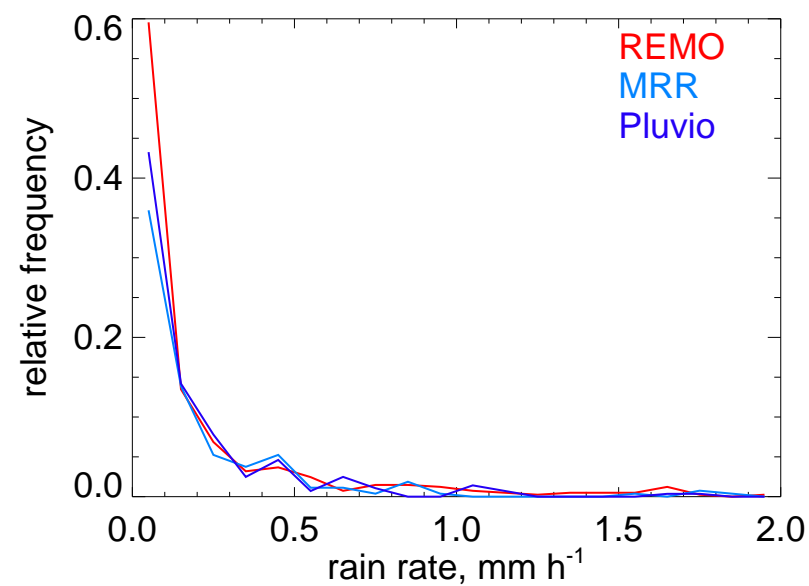

Fig. 22. Histogram of rain rates from REMO (red), MRR (light blue), and rain gauge network (blue).

with a suite of ground-based remote sensing systems and in-situ instruments were compared with corresponding parameters simulated by the regional model REMO. The comparison covers months from May to September.

A parameter-related interpretation of the results does not seem to be reasonable, so we try to summarise the results in the frame of related processes. The main conclusions from the comparison between observed and simulated water cycle parameters refer to two areas, boundary layer processes, and cloud and precipitation processes.

The simulated humidity field only agrees with observations in the lowest $1000 \mathrm{~m}$, i.e. in the atmospheric boundary layer (see Figs. 10 and 11). The daytime observations show that often the convective boundary layer reaches up to $2000 \mathrm{~m}$ which cannot be found in the model and causes the poor correlation in the layer between $1000 \mathrm{~m}$ and $2000 \mathrm{~m}$. The model boundary layer is too low, and the large positive bias in the ABL shows that it is too moist. One reason for this is a too large evaporation and a mostly too low sensible heat flux (Fig. 14). We calculate an average Bowen ratio, which is the ratio of sensible to latent heat flux, from observed fluxes which is 2.1 times the average Bowen ratio of model fluxes. A low sensible heat flux leads to a shallow boundary layer (see e.g., Batchvarova and Gryning, 1994), and a large latent heat flux increases the moisture content. The wrong partitioning of the available energy at the surface is probably caused by the unrealistic representation of soil moisture in the model (Fig. 15). On days after rain events the modelled and observed evaporation, humidity profiles and boundary layer height agree well (see Fig. 13, lower panel), but the model performance is not right in dry conditions. The simple bucket model for soil moisture cannot simulate the drying of the upper layers of the soil, and consequently, the decrease 
Table 5. Rain sum in mm from observations and REMO.

\begin{tabular}{lcc}
\hline & 11 May-17 June 2004 & 1 Sep-30 Sep 2004 \\
\hline REMO & 42.7 & 49.5 \\
MRR & 37.3 & 20.8 \\
PLUVIO & 48.5 & 30.7 \\
\hline
\end{tabular}

in evaporation and the right simulation of the boundary layer cannot be reproduced. The importance of soil parameters for the right prediction of atmospheric fluxes is widely acknowledged (e.g., Mölders, 2005). The process study clearly shows that the interaction of all relevant processes has to be analysed when assessing the deviations between model and observations.

The development of the boundary layer also has consequences for the formation of low-level clouds. Consistently, it is found that the modelled ABL clouds are lower than observed ABL clouds (see the discussion to Fig. 18 in Sect. 5.3). The comparison of the water vapour flux profiles shows that the vertical transport of water vapour in the CBL is simulated in the right way (Fig. 16). So boundary layer clouds arise near the top of the CBL which is too shallow in the model. The lower base of simulated ABL clouds compared to observations is also reported for other models (ECMWF, RACMO, RCA and LM) by Willén et al. (2005). The comparisons also show that the vertical extent of simulated ABL clouds is smaller than for observed clouds (Fig. 17). This may be a result of the parameterisation scheme, which may not be capable of extending the ABL clouds to more than a few levels. In reality, we observe a large variability of the top of boundary layer clouds.

Generally, REMO predicts too few clouds, both in cloud occurrence and in cloud cover (Fig. 18). In the region above $10 \mathrm{~km}$ the assessment of cloud representation becomes difficult because of shortcomings in the cloud radar data. Lowlevel cloud cover is underestimated by the model. Part of the differences between radar- and model-derived distributions can be explained by the discrepancy in deriving cloud parameters as discussed in Sect. 4.4. Concerning IWC, the lack of IWC values smaller than $10^{-6} \mathrm{~g} \mathrm{~m}^{-3}$ (Fig. 20) is probably due to the large threshold value of $80 \%$ relative humidity in the grid box for a cloud to form. This value depends on the horizontal grid size, and an adaptation based on observations may give smaller values. The comparison of LWC probably suffers from the insufficient algorithm for deriving LWC in water clouds (see Fig. 19). Drizzle in clouds can cause problems because it produces a large reflectivity which can be misinterpreted as a large cloud water content. This problem does not seem to be solved in a satisfactory manner. Rain rates are similar, but the representativeness of both observations and grid-box values is rather low.
The right representation of clouds in models appears to be essential for the right prediction of precipitation amount. In the present study we find in the REMO simulations too few clouds but a realistic rain amount (Sect. 5.5) within the range of uncertainty. The coupling of cloud cover to grid-box relative humidity is of course a possibility to tune the model to a more realistic cloud representation. But the present study in which both cloud amount and precipitation amount were validated by observations strongly recommends that the processes should be treated together in order to keep the parameterisation physically relevant.

The determination of several parameters - observed or modelled - which were compared in this study is presently improved or will be improved in the near future. Lidar humidity data are now available continuously (from $\mathrm{Au}$ gust 2005 on) and with this also night time parameters can be derived and ceilometer data can be replaced by data of the more sensitive backscatter lidar. With continuous lidar data there is a large potential for the use of more accurate algorithms, which combine radar and lidar for the discrimination of water clouds and ice clouds (e.g., Tinel et al., 2005). In the future the Doppler spectra measured by the cloud radar will be used for the discrimination of drizzle/rain and cloud droplets.

Some of the shortcomings found in parameterisation schemes in REMO are currently cleared up. REMO will be upgraded with a new scheme for cloud water calculation in which both cloud liquid water and cloud ice water content are treated prognostically with separate budget equation (Lohmann, 1995). The REMO soil moisture scheme which was found to be insufficient for dry periods is now extended to the five soil layers (S. Hagemann, personal communication).

There are also considerations to improve the parameterisation scheme of turbulent and convective vertical transport in the ABL. The transport is - as in most present-day regional models - parameterised by a diffusion equation where the flux is proportional to the local gradient of the transported quantity. It is known from measurements as well as from Large Eddy Simulations that in the CBL the gradient is equal or near to zero and the transport depends on bulk characteristics rather than on local gradients (Stull, 1988). Therefore a non-local parameterisation scheme like the one proposed by Holtslag and Boville (1993) may be more adequate and will be tested in REMO.

Acknowledgements. The Meteorological Observatory Lindenberg (German Meteorological Service) is acknowledged for providing the data of the ceilometer, the cloud radar MIRA-36, the micro rain radar and of the PLUVIO rain gauges. The authors would like to thank B. Brügmann, F. Jansen, K. Ertel, and A. Lammert for operating the lidar systems during the measuring campaigns. Thanks are also due to the participants of LITFASS-2003 for providing data (composite surface flux, soil moisture data). R. Podzun helped to run the model. 
The German Federal Ministry for Education and Research (BMBF) partly funded the work of B. Hennemuth under contract No. 01LD0103. Financial support for part of the lidar work by the German Meteorological Service is gratefully acknowledged.

Edited by: W. E. Asher

\section{References}

Baedi, R. J. P., de Wit, J. J. M., Russchenberg, H. W. J., Erkelens, J. S., and Baptista, J. P. V. P.: Estimating effective radius and liquid water content from radar and lidar based on CLARE'98 data-set, Phys. Chem. Earth (B), 25, 1057-1062, 2000.

Batchvarova, E. and Gryning, S.: An applied model for the height of the daytime mixed layer and the entrainment zone, BoundaryLayer Meteorol., 71, 311-323, 1994.

Beyrich, F. and Mengelkamp, T.: Evaporation over a heterogeneous land surface: EVA_GRIPS and the LITFASS-2003 experiment an overview, Boundary-Layer Meteorol., 121, 5-32, 2006.

Beyrich, F., Leps, J., Mauder, M., Bange, J., Foken, T., Huneke, S., Lohse, H., Lüdi, A., Meijninger, W., Mironov, D., Weisensee, U., and Zittel, P.: Area-averaged surface fluxes over the LITFASS region based on eddy-covariance measurements, Boundary-Layer Meteorol., 121, 33-65, 2006.

Bormotov, V., Peters, G., Schünemann, K., Vavriv, D., Vinogrdov, V., and Volkov, V.: A $36 \mathrm{GHz}$ Doppler radar for remote sensing of the atmosphere, in: Proceedings of Millennium Conference on Antenna and Propagation, Davos Switzerland, 9-14 April 2000, 2000

Bösenberg, J.: Ground-based differential absorption lidar for Watervapor and temperature profiling: methodology, Appl. Optics, 37 , 3845-3860, 1998.

Bösenberg, J.: Differential Absorption Lidar for Water Vapor and Temperature Profiling, in: Lidar-Range-Resolved Optical Remote Sensing of the Atmosphere, edited by: Weitkamp, C., pp. 213-240, Springer, New York, 2005.

Bösenberg, J. and Linné, H.: Laser remote sensing of the planetary boundary layer, Meteorol. Z., 11, 233-240, 2002.

Brooks, M., Hogan, R., and Illingworth, I.: A long term comparison of cloud properties observed by vertically pointing radar and lidar with their representation in operational NWP models, in: Proc. 14th Int. Conf. on Clouds and Precipitation, Bologna, Italy, 2004

Chiriaco, M., Vautard, R., Chepfer, H., Haeffelin, M., Didhia, J., Wanherdrick, Y., Morille, Y., and Protat, A.: The ability of MM5 to simulate ice clouds: Systematic compariosn between simulated and measured fluxes and lidar/radar profiles at the SIRTA Atmospheric Observatory, Mon Weather Rev., 134, 897-918, 2006.

Clothiaux, E. E., Miller, M. A., Albrecht, B. A., Ackermann, T. P., Verlinde, J., Babb, D. M., Peters, R. M., and Syrett, W. J.: An evaluation of a 94-GHz radar for remote sensing of cloud properties, J. Atmos. Ocean. Tech., 12, 201-229, 1995.

Crewell, S., Bloemink, H., Feijt, A., García, S., Jolivet, D., Krasnov, O., van Lammeren, A., Löhnert, U., van Meijgaard, E., Meywerk, J., Quante, M., Pfeilsticker, K., Schmidt, S., Scholl, T., Simmer, C., Schröder, M., Trautmann, T., Venema, V., Wendisch, M., and Willén, U.: The BALTEX BRIDGE campaign - An in- tegrated approach for a better understanding of clouds, B. Am. Meteorol. Soc., 85, 1565-1584, 2004.

DKRZ: The ECHAM3 atmospheric general circulation model, Techn. Report 6, Deutsches Kimarechenzentrum, Hamburg, Germany, 1994.

Dümenil, L. and Todini, E.: A rainfall-runoff scheme for use in the Hamburg climate model, in: Advances in Theoretical Hydrology, A Tibute to James Dooge, edited by: O'Cane, J., Europ. Geophys. Soc. Ser. Hydrolog. Sciences (1), pp. 129-157, Elsevier Press, Amsterdamm, The Netherlands, 1992.

Ertel, K.: Application and Development of Water Vapor DIAL Systems, Dissertation Univ. Hamburg, http://www.sub.uni-hamburg. de/opus/frontdoor.php?source_opus=2007, p. 128, 2004.

Fox, N. and Illingworth, A.: The retrieval of stratocumulus cloud properties by ground-based cloud radar, J. Appl. Met., 36, 485492, 1997.

Gaussiat, N., Sauvageot, H., and Illingworth, A.: Cloud liquid water and ice content retrieval by multiwavelength radar, J. Atmos. Ocean. Tech., 20, 1264-1275, 2003.

Haeffelin, M., Barthés, L., Bock, O., Boitel, C., Bouniol, D., Chepfer, H., Chiriaco, M., Cuesta, J., Delanoë, J., Dobrinski, P., Dufresne, J.-L., Flamant, C., Grall, M., Hodzic, A., Hourdin, F., Lapouge, F., Lemaitre, Y., Mathieu, A., Morille, Y., Naud, C., Noël, V., O'Hirok, W., Pelon, J., Pietras, C., Protat, A., Romand, B., Scialom, G., and Vautard, R.: SIRTA, a ground-based atmospheric observatory for cloud and aerosol research, Ann. Geophys., 23, 253-275, 2005, http://www.ann-geophys.net/23/253/2005/.

Hennemuth, B. and Lammert, A.: Determination of the atmospheric boundary layer height from radiosonde and lidar backscatter, Boundary-Layer Meteorol., 120, 181-200, 2006.

Hogan, R., Jakob, C., and Illingworth, A.: Comparison of ECMWF winter-season cloud fraction with radar-derived values, J. Appl. Meteorol., 40, 513-525, 2001.

Hogan, R., Illingworth, A., O’Connor, E., and Baptista, J. P.: Characteristics of mixed-phase clouds Part II: A climatology from ground-based lidar, Q. J. R. Meteorol. Soc., 129, 1-18, 2003.

Hogan, R., Mittermaier, M., and Illingworth, A.: The retrieval of ice water content from radar reflectivity factor and temperature and its use in in evaluating a mesoscale model, J. Appl. Meteorol., 45, 301-317, 2006.

Holtslag, A. A. and Boville, B. A.: Local versus non-local boundary-layer diffusion in a global climate model, J. Climate, 10, 1825-1842, 1993.

Intrieri, J., Shupe, M. D., Uttal, T., and McCarty, B. J.: An annual cycle of Arctic cloud characteristics observed by radar and lidar at SHEBA, J. Geophys. Res., 107(C10), 8029, doi:10.1029/2000JC000423, 2002

Jacob, D.: A note to the simulation of the annual and inter-annual variability of the water budget over the Baltic Sea drainage basin, Meteorol. Atmos. Phys., 77, 61-73, 2001.

Jacob, D., den Hurk, B. V., Andræ, U., Elgered, G., Fortelius, C., Graham, L., Jackson, S., Karstens, U., Köpken, C., Lindau, R., Podzun, R., Rockel, B., Rubel, F., Sass, B., Smith, R., and Yang, $\mathrm{X}$.: A comprehensive model inter-comparison study investigating the water budget during the BALTEX-PIDCAP period, Meteorol. Atmos. Phys., 77, 19-43, 2001.

Krasnov, O. and Russchenberg, H.: An enhanced algorithm for the retrieval of liquid water cloud porperties from simultaneous radar 
and lidar measurements. Part 1: The basic analysis of in situ measured drop size spectra, in: European conferenxe on Radar Meteorology ERAD 2002, 18-22 November 2002, ERAD Publication Series, 1, Delft, The Netherlands, 2002.

Krasnov, O. and Russchenberg, H.: Retrieval of the LWC in water clouds with radar and lidar, in: Proc. Sixth Int. Symposium on Tropospheric Profiling, Needs and Technologies, 14-20 September 2003, Leipzig, Germany, 2003.

Krasnov, O. and Russchenberg, H.: A synergetic radar lidar technique for the LWC retrieval in water clouds, in: COST 720 Final Symposium, Toulouse, Toulouse, France, 15-18 May 2006, 2006.

Lammert, A. and Bösenberg, J.: Determination of the convective boundary layer height with laser remote sensing, Bound.-Lay. Meteorol., 119, 159-170, 2006.

Linné, H., Hennemuth, B., Bösenberg, J., and Ertel, K.: Water vapour flux profiles in the convective boundary layer, Theor. Appl. Climatol., 87, 201-211, 2007.

Liu, C.-L. and Illingworth, A.: Toward more accurate retrievals of ice water content from radar measurements of clouds, J. Appl. Meteorol., 39, 1130-1146, 2000.

Lohmann, U., Roeckner, E.: Introduction of a prognostic cloud ice scheme in the ECHAM general circulation model: Impact on climate and climate sensitivity, Report 179, Max-Planck-Inst. f. Meteorologie, Hamburg, Germany, 1995.

Louis, J. F.: A parametric model of vertical eddy fluxes in the atmosphere, Bound.-Lay. Meteorol., 17, 187-202, 1979.

Löhnert, U., Crewell, S., and Simmer, C.: An integrated approach toward retrieving physically consistent profiles of temperature, humidity and cloud liquid water, J. Appl. Meteorol., 43, 12951307, 2004.

Mahrt, L.: Mixed layer moisture structure, Mon. Weather Rev., 104, 1403-1407, 1976.

Mauder, M., Liebethal, C., Gckede, M., Leps, J., Beyrich, F., and Foken, T.: Processing and quality control of flux data during LITFASS-2003, Bound.-Lay. Meteorol., 121, 67-88, 2006.

Mengelkamp, H.-T., Beyrich, F., Heinemann, G., Ament, F., Bange, J., Berger, F., Bösenberg, J., Foken, T., Hennemuth, B., Heret, C., Huneke, S., Johnsen, K.-P., Kerschgens, M., Kohsiek, W., Leps, J.-P., Liebethal, C., Lohse, H., Mauder, M., Meijninger, W., Raasch, S., Simmer, C., Spieß, T., Tittebrand, A., Uhlenbrock, J., and Zittel, P.: Evaporation over a heterogeneous land surface, B. Am. Meteorol. Soc., 87, 775-786, 2006.

Meywerk, J., Quante, M., and Sievers, O.: Radar based remote sensing of cloud liquid water - application of various techniques - a case stdy, Atmos. Res., 75, 167-181, 2005.

Mölders, N.: Plant- and soil-parameter-caused uncertainty of predicted surface fluxes, Mon. Weather Rev., 133, 3498-3516, 2005.

Neisser, J., Adam, W., Beyrich, F., Leiterer, U., and Steinhagen, H.: Atmospheric boundary layer monitoring at the Meteorological Observatory Lindenberg as a part of the 'Lindenberg Column': Facilities and selected results, Meteorol. Z., 11, 241-253, 2002.

Nordeng, T.: Extended versions of the convective parametrization scheme at ECMWF and their impact on the mean and transient activity of the model in the tropics, Technical Momorandum 206, ECMWF Research Department, Reading, UK, 1994.

Parlange, M., Eichinger, W., and Albertson, J.: Regional scale evaporation and the atmospheric boundary layer, Rev. Geophys., 33, 99-124, 1995.
Peters, G., Fischer, B., and Andersson, T.: Rain observations with avertically looking Micro Rain Radar (MRR), Boreal Environm., 7, 353-362, 2002.

Peters, G., Fischer, B., Münster, H., Clemens, M., and Wagner, A.: Profiles of raindrop size distributions as retrieved by microrain radars, J. Appl. Meteorol., 41, 1930-1949, 2005.

Protat, A., Armstrong, A., Haeffelin, M., Morille, Y., Pelon, J., and Delanoë, J.: Impact of conditional sampling and instrumental limitations on the statistics of cloud properties derived from cloud radar and lidar at SIRTA, Geophys. Res. Lett., 33, L11805, doi:10.1029/2005GL025340, 2006.

Rockel, B., Raschke, E., and Weyres, B.: A parameterization of broad band radiative transfer properties of water, ice and mixed clouds, Contr. Atmos. Phys., 64, 1-12, 1991.

Roeckner, E., Arpe, K., Bengtsson, L., Christoph, M., Claussen, M., Dümenil, L., Esch, M., Giorgetta, M., Schlese, U., and Schulzweida, U.: The atmospheric general circulation model ECHAM-4: Model description and simulation of present day climate, Report 218, Max-Planck-Inst. f. Meteorologie, Hamburg, Germany, 1996.

Russchenberg, H., Crewell, S., Loehnert, U., Quante, M., Meywerk, J., Baltink, H. K., and Krasnov, O.: Radar observations of stratocumulus compared with in situ aircraft data and simulations, in: Proc. ERAD 2004 Visby, pp. 296-300, Visby, Sweden, 2004.

Sassen, K.: Ice cloud content from radar reflectivity, J. Clim. Appl. Meterol., 25, 1050-1053, 1987.

Sauvageot, H. and Omar, J.: Radar reflectivity of cumulus clouds, J. Atmos. Ocean. Tech., 4, 264-272, 1987.

Sengupta, M., Clothiaux, E., and Ackerman, T.: Climatology of warm boundary layer clouds at the ARM SGP site and their comparison to models, J. Climate, 17, 4760-4782, 2004.

Stull, R.: An introduction to boundary layer meteorology, Kluwer Academic Publisher, Dordrecht, 1988.

Sundqvist, H.: A parameterization scheme for non-convective condensation including prediction of cloud water content, Q. J. R. Meteorol. Soc., 104, 677-690, 1978.

Tiedtke, M.: A comprehensive mass flux scheme for cumulus parameterization in large-scale models, Mon. Weather Rev., 117, 1779-1800, 1989.

Tinel, C., Testud, J., Pelon, J., Hogan, R., Protat, A., Delanoë, J., and Bouniol, D.: The retrieval of ice-cloud properties from cloud radar and lidar synergy, J. Appl. Meteorol., 44, 860-874, 2005.

van Meijgaard, E. and Crewell, S.: Comparison of model predicted liquid water path with ground-based measurements during CLIWA-NET, Atmos. Res., 75, 201-226, 2005.

Willén, U., Crewell, S., Baltink, H. K., and Sievers, O.: Assessing model predicted vertical cloud structure and cloud overlap with radar and lidar ceilometer observations for the Baltex Bridge Campaign of CLIWA-NET, Atmos. Res., 75, 227-255, 2005.

Wulfmeyer, V. and Bösenberg, J.: Ground-based differential absorption lidar for water-vapor and temperature profiling: assessment of accuracy, resolution, and meteorological applications, Appl. Opt., 37, 3825-3844, 1998. 